\title{
Liquefaction resistance of unsaturated sands: experimental evidences and theoretical interpretation
}

\author{
Mele L.*, Tan Tian J..*, Lirer S. ${ }^{* \star *}$, Flora A. ${ }^{*}$ Koseki J. ${ }^{* *}$ \\ *University of Napoli, Federico II (Napoli, Italy); \\ **University of Tokyo (Tokyo, Japan); \\ ***University of Rome, Guglielmo Marconi (Rome, Italy).
}

\begin{abstract}
Cyclic undrained triaxial tests were carried out on saturated and unsaturated loose specimens of three fine grained materials. The results confirm that as the saturation degree decreases, liquefaction resistance sharply increases. In the interpretation of results, the first step was the assessment of the reliability of the use of the $5 \%$ strain amplitude criterion to define the attainment of liquefaction. To this aim, the tests were analyzed assuming that the soil behaves as an equivalent viscous material. It is shown that the characteristic values of viscosity defining the start and completion of liquefaction depend on soil grading, increasing as the coefficient of uniformity increases. The equivalent viscosity corresponding to a condition of double strain axial amplitude of $5 \%$ is rather constant for all soils. Then, starting from the observation of the relationship between the final volumetric strain and the initial degree of saturation, a theoretical interpretation of the tests is reported. It is shown that the behavior of the tested sands can be interpreted quantifying the thermodynamic specific energy spent to reach liquefaction, considering the contribution of all phases (soil, water and air). The position of the liquefaction resistance curve depends on the volumetric component of such a specific energy.
\end{abstract}

Keywords: Laboratory tests; liquefaction, partial saturation.

\section{List of notation}

$B \quad$ Skempton coefficient

CRR cyclic resistance ratio 
$C R R_{\text {sat }}$ cyclic resistance ratio required causing liquefaction at 20 cycles in full saturation $C R R_{\text {unsat }}$ cyclic resistance ratio required causing liquefaction at 20 cycles in partial saturation

CSR cyclic stress ratio

$D \quad$ area of the cycle in the plane $\varepsilon$ s:q

Dc degree of compaction

$\mathrm{Dr} \quad$ relative density

$D_{50} \quad$ average particles size

e void ratio index

$E_{\text {air }}$ specific energy of deformation of the air

$e_{\max } \quad$ maximum void ratio

$e_{\min } \quad$ minimum void ratio

$e_{0} \quad$ void ratio at the end of consolidation phase

$E_{s, l i q}$ distorsional specific energy at liquefaction

$E_{s k} \quad$ specific energy of deformation of soil skeleton

$E_{s, s k}$ distorsional specific energy of soil skeleton

$E_{\text {tot }}$ total specific energy of deformation

$E_{\text {tot,liq }}$ specific energy of deformation needed to reach liquefaction

$E_{v, l i q} \quad$ volumetric specific energy needed to reach liquefaction

$E_{v, s k} \quad$ volumetric specific energy of soil skeleton

$E_{w} \quad$ specific energy of deformation of air

Gs specific gravity

$L R R, 15$ liquefaction resistance ratio (15 cycles)

$N_{c y c} \quad$ number of loading cycles

$N_{\text {liq }} \quad$ number of cycles to reach liquefaction

$p^{\prime} \quad$ average principal effective stress

$q_{d} \quad$ cyclic deviatoric stress

$q_{\max }$ maximum deviatoric stress for each cycle

$q_{\min } \quad$ minimum deviatoric stress for each cycle

$R_{u} \quad$ pore pressure ratio

$s \quad$ suction $\left(=\mathrm{u}_{\mathrm{a}}-\mathrm{u}_{\mathrm{w}}\right)$

$S_{r} \quad$ degree of saturation

$S_{r}$,liq degree of saturation when liquefaction occurs $\left(\varepsilon_{D A}=5 \%\right)$

$S_{\text {ro }} \quad$ degree of saturation at the end of consolidation phase

$u_{a} \quad$ air pore pressure

$u_{a, \text { liq }} \quad$ air pore pressure when liquefaction occurs $\left(\varepsilon_{\mathrm{DA}}=5 \%\right)$

$u_{w} \quad$ water pore pressure

$U_{c} \quad$ coefficient of uniformity

$\Delta u \quad$ excess pore pressure

$\varepsilon a \quad$ axial strain

$\varepsilon D A \quad$ axial strain (double amplitude) 


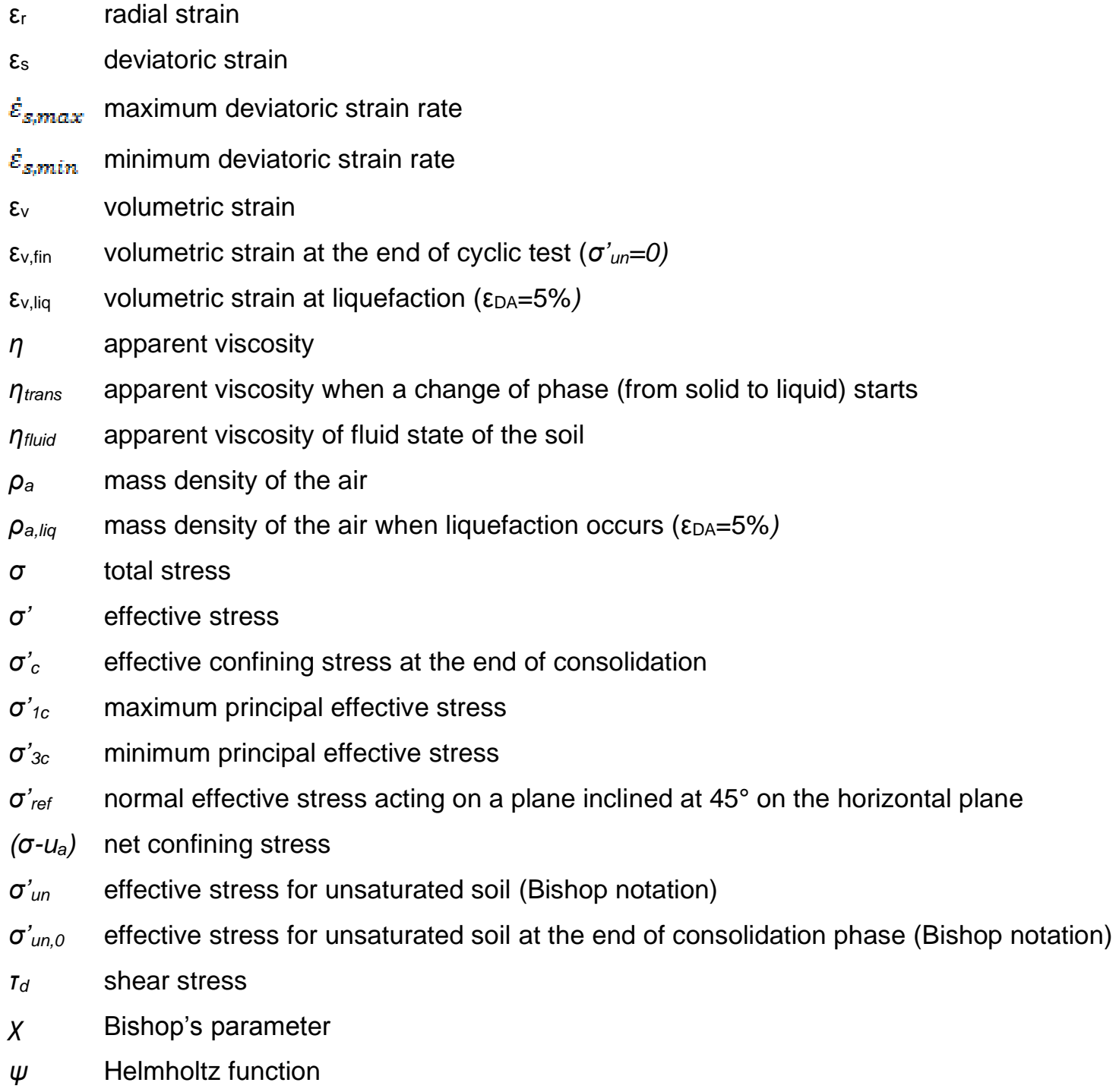




\section{Introduction}

Liquefaction is a phenomenon marked by a rapid loss of soil strength, which can occur in loose, saturated soil deposits subjected to earthquake shaking or other forms of rapid loading. During liquefaction, when the effective stresses approach zero, soil behavior switches from that of a solid to that of a fluid. Soil liquefaction can cause serious damage to engineering structures and, as a consequence, many types of mitigation techniques (densification, drainage, addition of fines, etc.) have been developed. Among these, the "Induced Partial Saturation" (IPS) is considered one of the most innovative and promising ones. IPS increases the resistance to liquefaction of the liquefaction-susceptible soil by introducing some amount of air/gas in the voids (Eseller Bayat et al., 2012). Laboratory results have shown that even a small reduction in the degree of saturation of an initially saturated sand can have a relevant effect (Chaney, 1978; Yoshimi, 1989; Yegian et al., 2007; Ishihara et al., 2002). Yegian et al. (2007), for instance, showed that even a small decrease of the degree of saturation (from 100 to 98\%) can increase the resistance to liquefaction by $30 \%$.

The presence of air in the voids increases the resistance against liquefaction in two ways (Okamura and Soga, 2006): the first mechanism is connected to the very low volumetric stiffness of gases, because of which during undrained loading there is a volumetric reduction of the gas phase and therefore reduced excess pore pressures. This mechanism is the ruling one for high degrees of saturation (i.e. dispersed air bubbles). The second mechanism is due to the matric suction of unsaturated soils, which increases the stiffness and strength of soils (Bishop and Blight, 1963). This latter mechanism becomes relevant when the degree of saturation is low enough to have a continuous air phase.

Okamura and Soga (2006) suggest that the liquefaction resistance of unsaturated sands should depend on the initial confining pressure and the initial pore pressure, and there is a unique relationship between the normalized liquefaction resistance and the potential volumetric strain (i.e. the volumetric strain at which liquefaction is triggered): therefore, the liquefaction resistance of a partially saturated soil can be quantified from the one of the saturated soil by estimating the potential volumetric strain caused by the gas phase. However, Wang et al. (2016a) 
experimentally observed that in some cases (for instance for Inagi sand, one of the sands tested in this work) these approaches lead to overestimate soil resistance to liquefaction.

In this paper, the effectiveness of induced partial saturation on liquefaction resistance has been experimentally verified by means of cyclic triaxial tests. Some of the cyclic tests on saturated specimens were carried out at the University of Napoli Federico II, while all the cyclic tests on unsaturated specimens were done at the University of Tokyo, in the framework of a scientific cooperation between the two institutions. Attention was initially given to the triggering of liquefaction, to check which of the available conventional methods should be preferred. To this aim, soil behavior under cyclic loading has been analyzed following the approach proposed by Chen et. al (2016), who suggest to consider the soil as an equivalent viscous material, thus looking at the evolution of the apparent coefficient of viscosity during the test to check when liquefaction has been triggered.

Starting from the experimental observations by Okamura and Soga (2006), finally, an energetic approach is proposed to quantify the resistance to liquefaction of unsaturated soils.

\section{Material, testing programme and equipments}

\subsection{Materials}

The sand used in this research comes from an area (Sant'Agostino-Ferrara, Italy) located in Emilia Romagna region, that was affected by extensive liquefaction phenomena during the 2012 earthquake. The soil samples (named Sant'Agostino Sand, SAS) were retrieved at a depth between $6.8 \mathrm{~m}$ and $8 \mathrm{~m}$ from the ground level. The sand is composed mainly by quartz, along with feldspar and calcite, as deduced from x-ray diffraction test.

Two other types of materials were used in this study, namely Bauxite and Inagi Sand, to confirm the findings of SAS. Bauxite is an aluminum ore (main source of aluminum). In this paper, Bauxite was obtained from Australia through a Japanese company. Inagi Sand, on the other hand, is an inland weathered sand widely found in the Tama district in the west of Tokyo, Japan. 
This sand consists of crushable particles and can be classified as silty sand with considerable amount of fines. The material properties are shown in Table 1, while the grain size distribution curves are shown in Figure 1.

The value of $e_{\max }$ and $e_{\min }$ of Bauxite could not be determined using the Japanese standard test because of the high fines content $(40.6 \%)$, for this reason the degree of compaction $\left(D_{c}\right)$ was considered instead of the relative density $\left(D_{r}\right)$.

Figure 2 reports the water retention curve of the soils. The curves of Bauxite and Inagi sand were obtained via Hanging Column Method. This Method was innovated at the University of Tokyo and is applicable for low suction range (up to $20 \mathrm{kPa}$ ). Inagi Sand was prepared at Degree of Compaction $\left(D_{c}=72 \%\right)$ while Bauxite at $D_{c}=81 \%$. For Sant'Agostino sand, the SWRC $\left(D_{r}=50 \%\right)$ was obtained through a Ku-pf apparatus at the University of Napoli.

\subsection{Testing programme and equipments}

Seven undrained cyclic triaxial tests (Table 2) using SAS were performed in a stress control mode, on fully saturated specimens in a Bishop \& Wesley triaxial cell on specimens having diameter of $38 \mathrm{~mm}$ and height of $76 \mathrm{~mm}$. The specimens were prepared at different initial relative density $\left(D_{r}\right)$ by wet pluviation. The saturation phase was obtained in the TX apparatus imposing a low isotropic confining effective stress of $10 \mathrm{kPa}$ in drained condition. After the saturation phase (Skempton Coefficient B>0.98), the specimens were isotropically consolidated with a confining stress $\left(\sigma_{c}^{\prime}\right)$ of about $50 \mathrm{kPa}$ and then the cyclic phase was carried out imposing, after the isotropic consolidation phase, different Cyclic Stress Ratio (CSR) (Table 2), defined as the ratio between the shear stress $T_{d}$ and the normal effective stress acting on a plane inclined at $45^{\circ}$ on the horizontal plane $\sigma^{\prime}{ }^{\prime}$ :e:

$C S R=\frac{\tau_{d}}{\sigma_{r e f}^{\prime}}=\frac{q_{d}}{2 \cdot \sigma_{r e f}^{\prime}}$

1. 
where $q_{d}$ is the cyclic deviatoric stress.

By definition, $\sigma^{\prime}$ ref is equal to:

$$
\sigma_{r e f}^{\prime}=\frac{\sigma_{1, c}^{\prime}+\sigma_{3, c}^{\prime}}{2}
$$

2.

Where $\sigma_{1, c}^{\prime}$ and $\sigma_{3, c}^{\prime}$ are respectively the maximum and the minimum principal effective stresses acting on the specimen at the end of the consolidation phase. In isotropically consolidated tests, $\sigma^{\prime}$ ref is equal to the confining cell pressure $\left(\sigma_{c}^{\prime}\right)$, and as a consequence:

$$
C S R=\frac{q_{d}}{2 \cdot \sigma_{c}^{\prime}}
$$

3.

At the laboratory of the University of Tokyo, undrained cyclic triaxial tests were carried out on saturated and unsaturated specimens of Bauxite, and Inagi and SAS sand (Tables 2 and 3) with the Linkage Double Cell System (Figure 3, Wang et al. 2016b). The tests were performed on reconstituted specimens having a diameter of $50 \mathrm{~mm}$ and a height of $100 \mathrm{~mm}$ : a vertical sinusoidal cyclic load was applied by a double action cylinder controlled by a function generator and an E/P regulator. The pore water pressure $\left(U_{w}\right)$ is measured by a pressure transducer while the pore air pressure $\left(u_{a}\right)$ is measured by another pressure transducer connected to the top cap, on which a hydrophobic filter is glued, while a thin membrane filter is used on the traditional porous stone to minimize the time required to reach the equalization of the pressures into the specimen, as compared to the alternative of using a high entry value porous stone (Nishimura et al. 2012). Volume changes of the unsaturated specimens are measured by considering change of water level in the inner cell and movement of the top cap. In order to interpret the results, the tests have been listed in Table 3 dividing them in two groups, with two average degrees of 
saturation $\left(\mathrm{S}_{\mathrm{r}}\right)$ for Sant' Agostino Sand: $55 \%$ and $87 \%$. Corresponding tests were also conducted for Bauxite (BA) under $S_{r}=57 \%$ and $85 \%$, and Inagi Sand $(\mathrm{IN})$ under $\mathrm{S}_{\mathrm{r}}=50 \%$. In the following, therefore, reference will be done to the average degree of saturation.

For high values of $\mathrm{S}_{r}$, the pore air pressure $u_{a}$ was not measured. However, in such conditions it is reasonable to consider that the air phase is not continuous (i.e. air bubbles are dispersed into water), and therefore for thermodynamic equilibrium the air pressure is equal to the pore water pressure. For the specimens having a lower degree of saturation, in which on the contrary the air phase is likely to be continuous, the air pore pressure was measured.

In order to interpret the cyclic tests on unsaturated specimens, it is necessary to consider the relevant stress variables. As well known, in unsaturated soils it is still possible to define an effective stress. The way to define such a stress depends on the saturation degree, or better on the continuity of the air phase: when the degree of saturation is high (say $\mathrm{Sr}>80 \%$ for fine sands, see for instance Tsukamoto et al. 2014) the air phase is occluded, i.e. air bubbles are trapped within the continuous water phase; when on the contrary the saturation degree is lower, the air domain is continuous. In the previous case, Terzaghi's definition can be used, while in the latter the effect of suction has to be taken into account. Among the different proposals, the most used one to this aim is probably that proposed by Bishop a long time ago (Bishop and Blight, 1963):

$$
\sigma_{u n}^{\prime}=\left(\sigma-u_{a}\right)+\chi\left(u_{a}-u_{w}\right)
$$

4.

where $\sigma$ is the total stress and $u_{a}, u_{w}$ and $x$ represent respectively the pore air pressure, the pore water pressure and the material parameter accounting for the effect of the degree of saturation (Bishop's parameter). The term $\left(\sigma-u_{a}\right)$ is called "net stress", while $\left(u_{a}-u_{w}\right)$ is the well known "suction" (s). Several definitions of the parameter $x$ have been proposed by researchers (e.g. Bishop and Blight, 1963; Vanapalli et al., 1996; Gallipoli et al. 2002), in this paper, it will be 
assumed that $X=S_{r}$ (Wheeler et al., 2003; Gallipoli et al., 2003). Given the Bishop notation of effective stress (Equation 4), an unsaturated soil reaches liquefaction when the effective stress state reaches zero during undrained cyclic loading.

As well known, the attainment of liquefaction can be conventionally defined either in terms of measured pore pressure increments $\Delta u$ (typically assuming that the soil liquefies when the pore pressure ratio $R_{u} \geq 0.9$, where $R_{u}=\Delta u / \sigma_{c}^{\prime}$ ), or in terms of axial strain (typically assuming that the soil liquefies when $\varepsilon_{D A} \geq 5 \%$, where $\varepsilon_{D A}$ is the double amplitude axial strain).

\section{Experimental Results}

\subsection{Cyclic triaxial tests}

\subsubsection{Tests on saturated specimens}

In the undrained cyclic triaxial tests (Table 2), the axial load was applied through uniform symmetrical sinusoidal cycles with constant amplitude with a frequency of $0.008 \mathrm{~Hz}$. As an example, the results of the cyclic test S_SA7 are plotted in Figure 4 in the four typical planes: $q$ vs. $\varepsilon_{a}, q$ vs. p', CSR vs $R_{u}$ and vs $N_{c y c}$ and $\varepsilon_{a}$ vs $N_{c y c}$. As well known, there is no effect of the loading frequency in undrained cyclic tests on saturated specimens, as long as it does not imply inertial effects (Tatsuoka et al., 1986).

During cyclic loading, the pore pressure increases (Figure 4(b)) and the stress path moves to the origin of the axes (Figure 4(c)). In this case liquefaction occurs after 15 cycles $\left(N_{\text {liq }}=15\right)$, when either the pore pressure ratio $\left(R_{u}\right)$ or the double amplitude strain reach the threshold previously mentioned $\left(\mathrm{R}_{\mathrm{u}}=0.9 ; \varepsilon_{\mathrm{DA}}=5 \%\right)$. In this test, and in all the tests carried out on saturated specimens, the two criteria of liquefaction give similar results (Table 4), while this will not be the case for unsaturated specimens.

\subsubsection{Tests on unsaturated specimens}

In the cyclic tests carried out on unsaturated specimens $\left(53 \%<\mathrm{S}_{r}<90 \%\right.$, Table 3$)$, the sinusoidal loading was applied with a frequency of $0.1 \mathrm{~Hz}$. Even though this frequency is higher than the one adopted in the Bishop \& Wesley cell, it is still low enough to ensure the equalization of the air and water pressures, as shown by Nishimura et al. (2012). 
The results of one of these tests (U_SA3) are plotted in Figure 5, in the four planes: q vs. $\varepsilon_{a} ; \mathrm{q}$ vs. $\left(\sigma-u_{a}\right) ; u_{a}, u_{w}$ and $s$ vs $N_{c y c}$, and finally $\varepsilon_{a}$ vs $N_{c y c}$.

In particular, it is interesting to observe Figure 5(b), where the pore water pressure $\left(u_{w}\right)$, pore air pressure $\left(\mathrm{u}_{\mathrm{a}}\right)$ and suction $(\mathrm{s})$ are plotted versus the number of cycles: it can be noted that the suction is always extremely low, cycling around zero, and accordingly $u_{w}$ and $u_{a}$ increase together.

In this test, according to the strain criterion $(\varepsilon D A=5 \%)$ liquefaction occurs at 26 cycles (Figure $5(d))$ but considering the stress criterion $\left(R_{u}=0.9\right)$ liquefaction is attained at 34 cycles.

In the tests carried out on specimens with $\mathrm{S}_{\mathrm{r}} \approx 55 \%$, the two criteria don't give the same result, while for specimens having $\mathrm{S}_{\mathrm{r}} \approx 87 \%$, as for the saturated ones, the two criteria give quite similar value of $\mathrm{N}_{\text {liq }}$ (Table 5).

All the results obtained on unsaturated specimens have been summarized in Table 5 .

The difference observed in the application of the two criteria for the specimens having the lowest value of $\mathrm{S}_{r}$ poses a problem on which criterion should be preferred. From a mechanical point of view, when liquefaction fully develops the soil state has to change, passing from that of a granular medium to that of a fluid. Then, such a change of state can be analysed by considering an equivalent viscous material, as suggested by Chen et al. (2016), with an apparent viscosity $(\eta)$ defined for each cycle as:

$$
\eta=\frac{q_{\max }-q_{\min }}{\bullet}
$$

5. 
where $q_{\max }$ and $q_{\min }$ are the maximum and minimum deviatoric stresses for the considered cycle, and $\dot{\varepsilon}_{s, \max }$ and $\dot{\varepsilon}_{s, \min }$ (with $\varepsilon_{s}=2 / 3 \cdot\left(\varepsilon_{\alpha}-\varepsilon_{r}\right)$ ) are the corresponding values of the deviatoric strain rates.

The apparent viscosity can be used to identify when liquefaction (physically intended as a change of state) is triggered. Actually, the process is not immediate. Figure 6 sketches the expected trend of $\eta$ with the number of cycles $\left(\mathrm{N}_{\mathrm{cyc}}\right)$ : during the first cycles, pore pressures start to develop and therefore the effective stress decreases; the soil is behaving under cyclic loading as a solid, but $\eta$ (Equation 5) slightly decreases because soil stiffness is decreasing. When a change of phase from solid to liquid starts to take place (for $\eta=\eta$ trans), a sharp decrease of the apparent viscosity is expected. Theoretically, this should be a sudden, complete drop to a minimum value. However, it must be expected that a transition phase with a high rate of reduction of $\eta$ is needed to fully reach the fluid state. When this is fully attained, a minimum value $\eta$ fluid is reached (Figure 6). For each unsaturated test the apparent viscosity was plotted with $\mathrm{N}_{\mathrm{cyc}}$ (Figure 7). In the figure, the conditions corresponding to the conventional definition of liquefaction are also highlighted. The shape of the experimental curves in Figure 7 is similar to the one sketched in Figure 6. Three different behaviours (solid, transition and fluid) can be clearly identified. For each soil, $\eta_{\text {trans }}$ seems to have a unique value, regardless of the degree of saturation. On the contrary, the value of $\eta_{\text {fluid }}$ is not constant, likely depending on $S_{r}$ (Figure 7). In particular, the tests with a lower value of $S_{r}$ show a higher value of nfluid. Furthermore, the slope of the curve $\eta-N_{c y c}$ in the transition phase seems to depend on the CSR and $\mathrm{S}_{\mathrm{r}}$.

The average values of $\eta_{\text {trans }}$ and $\eta_{\text {fluid }}$ for the tests of each material are reported in Table 6. Interestingly, both $\eta_{\text {trans }}$ and $\eta_{\text {fluid }}$ depend on the uniformity coefficient $\left(U_{c}\right)$ : for lower values of the coefficient of uniformity (i.e. less graded materials) $\eta_{\text {trans }}$ and $\eta_{\text {fluid }}$ decrease.

Another interesting evidence is that, for all the tested soils, $\eta(\varepsilon D A 5 \%)$ assumes value in a very narrow range $(963.4 \leq \eta(\varepsilon D A 5 \%) \leq 1406.2 \mathrm{kPa} \cdot \mathrm{s})$. A constant value $\eta(\varepsilon \mathrm{DA} 5 \%)=1185 \mathrm{kPa} \cdot \mathrm{s}$ can be assumed. On the contrary, $\eta$ Ru (lower than $\eta(\varepsilon D A 5 \%))$ varies from soil to soil and also, for a given 
soil, depending on the degree of saturation. Because of this, in the following the strain criterion will be preferred.

\subsection{Liquefaction resistance curves}

The liquefaction resistance curves (CRR-Nliq) obtained on SAS specimens are plotted in Figures $8(a)$ and (b), for the two mean values of the initial relative density $D_{r}\left(D_{r}=50 \div 60 \%\right)$ and two mean value of $\mathrm{S}_{\mathrm{r}}(55$ and $87 \%)$. The figure clearly shows the relevant role played by the degree of saturation $\mathrm{S}_{\mathrm{r}}$ : for each relative density, the liquefaction resistance curve of the unsaturated specimens $\left(55 \%<\mathrm{S}_{\mathrm{r}}<87 \%\right)$ is much higher than that obtained on saturated specimens. In the figure 8(a), a test conducted in the Japanese cell on a saturated SAS specimen is also reported (test S_SAJ in Table 2), to show the consistency of results obtained with the two apparatuses.

Similar plots are shown in Figure 9 and Figure 10 for Bauxite and Inagi sand, respectively. In all cases, the liquefaction resistance curves were significantly higher in the unsaturated condition.

The Liquefaction Resistance Ratio (LRR) can be defined as the ratio between the CRR of the unsaturated soil (CRRunsat) and the one of the saturated soil (CRRsat) at the same relative density and at the same number of cycles (LRR=CRRunsat/CRRsat). This parameter summarises the positive effect of desaturation on liquefaction resistance. In this paper, LRR was computed for the value $\mathrm{N}_{\mathrm{cyc}}=15$ (in the following named LRR,15). Its values are plotted versus the degree of saturation $\mathrm{S}_{\mathrm{r} 0}$ in Figure 11. Consistently with the results previously reported, LRR,15 increases as the degree of saturation decreases. Interestingly, the rate of increase is extremely high for the highest degrees of saturation, reducing towards the lower ones. This means that for a sand having a high initial degree of saturation, a very small reduction of $S_{r}$ is able to induce a significant increase of LRR, which is extremely interesting from an engineering point of view.

\subsection{Interpretation of experimental results}

\subsubsection{Volumetric strains}

As previously recalled, because of the Double Cell System (Figure 3), the volumetric strains $\varepsilon_{v}$ were measured during the tests performed on unsaturated specimens. An example of these 
measurements is plotted in Figure 12 for the U_SA2 tests (see Table 5): during the cycles, $\varepsilon_{v}$ increases with a rate that resembles that of the pore pressure (Figure 12(a)) or the net stress increments (Figure 12(b)). This may mean that the increase of $\varepsilon_{v}$ with the number of cycles due to the compressibility of air (because of the undrained condition), delaying the pore pressure build-up is at least one of the reasons of the increase of liquefaction resistance.

The volume strains measured in all unsaturated tests for SAS are plotted versus the number of cycles in Figure 13. It can be noted that during the cycles, $\varepsilon_{v}$ increases to a final value $\varepsilon_{v}$,fin which, being the confining stress the same $(50 \mathrm{kPa})$ for all tests, only depends on the initial degree of saturation (Figure 13): for given values of $S_{r}, D_{r}\left(\right.$ or e) and confining pressure ( $\sigma^{\prime}$ un), there is a unique value of $\varepsilon_{v, \text { fin, }}$ regardless of the applied CSR. Therefore, a unique final value of $\varepsilon_{\mathrm{v}, \text { fin }}$ exists for each set of $S_{r}, D_{r}\left(\right.$ or e) and $\sigma^{\prime}$ un.

The tests with $\mathrm{S}_{\mathrm{r}} \approx 55 \%$ reach $\varepsilon_{\mathrm{v}, \text { fin }} \approx 7 \%$, while the tests with $\mathrm{S}_{\mathrm{r}} \approx 87 \%$ reach a smaller value of the final volumetric strain $\left(\varepsilon_{v, \text { fin }}=3.5 \%\right)$. Consistently with what has been previously observed, it can be noted that for lower degree of saturation (Figure 13(a)), the final value of the volumetric strains doesn't correspond with the value of $\varepsilon_{v}$ attained at liquefaction $\left(\varepsilon_{v}\right.$,liq $)$, while for the higher degree of saturation (Figure $13\left(\right.$ b)) it does (i.e. $\varepsilon_{v, \text { fin }}=\varepsilon_{v}$,liq).

It is possible to write a theoretical relation between the final volumetric deformation and the initial degree of saturation applying Boyle's law (Okamura and Soga, 2006). In order to do so, it must be first recalled that in all tests, regardless of the initial value of $S_{r}$, the pore air pressure is always almost the same than to the pore water pressure (i.e. the suction can be considered always as being nihil, Figure $5(\mathrm{~b}))$. Then, the complete attainment of liquefaction must correspond to a condition in which both these pressures coincide with the total confining pressure $\left(u_{a}=u_{w}=\sigma\right)$, which means that the net stress is zero. The two conditions of net stress and suction being zero (that combination indicates that the effective stress in the Bishop notation, Equation 4, must be zero) imply the attainment of liquefaction phenomenon. Based on these considerations, Boyle's law allows to write the following equation: 


$$
\varepsilon_{v, f i n}=\frac{e_{0}}{1+e_{0}} \cdot\left(1-S_{r 0}\right) \cdot\left(1-\frac{u_{a, 0}}{\sigma}\right)
$$

6.

Equation 6 indicates that for given values of $D_{r}\left(\right.$ and $\left.e_{0}\right), \sigma$ and initial value of $S_{r 0}$, there is a

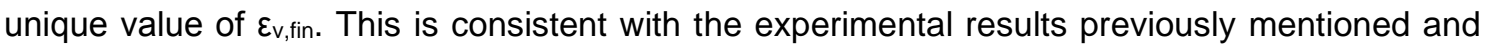
plotted in Figure 13. Obviously, for $\mathrm{S}_{\mathrm{r}}=100 \%$, the volumetric strain is zero.

In Figure 14 the experimental data have been plotted versus the initial degree of saturation Sr: it can be observed that Equation 6 (plotted using the average value of $e_{0}$ ) slightly underestimates the experimental values of $\varepsilon_{\mathrm{v}, \text { fin. }}$.

For each unsaturated test, the effective stress was plotted versus the volumetric strain (Figure 15). It can be noted (Figure 15(a)) that test results related to the same $S_{r}$ plot one over the other. All tests reach an effective stress, $\sigma^{\prime}$ un, equal to $0 \mathrm{kPa}$ at liquefaction, while as previously recalled the final volumetric strain depends on the initial degree of saturation. In Figure 15(b) the average curves for two different average degrees of saturation (55 and 87\%) are plotted. Such figures will be used in the following to simplify the computation of the energy components (see §3.3.2). The same results are plotted (Figure 16(a)) for other two materials: Bauxite with two degrees of saturation ( $\mathrm{Sr} \approx 55 \%$ and $85 \%$ ), and Inagi sand at $\mathrm{S}_{\mathrm{r}} \approx 50 \%$.

The results for all three materials are reported in Figure 16(a) and, in a non-dimensional plane $\left(\sigma^{\prime}{ }_{\text {un }} / \sigma_{\text {un, } 0: \varepsilon_{v} / \varepsilon_{v}, \text { fin }}\right)$ in Figure $16(\mathrm{~b})$. This latter figure shows the striking effectiveness of the proposed normalization, as all the results follow a unique trend. It then results that, during undrained cyclic tests, the relationship between $\sigma^{\prime}{ }_{u n} / \sigma^{\prime}{ }_{u n, 0}$ and $\varepsilon_{v} / \varepsilon_{v, \text { fin }}$ does not depend on soil intrinsic and state properties. In the following, therefore, it will be considered as a general law, having expression (Figure 16(b)): 


$$
\frac{\sigma_{u n}^{\prime}}{\sigma_{u n, 0}^{\prime}}=1-\left(\frac{\varepsilon_{v}}{\varepsilon_{v, f i n}}\right)^{1.7}
$$

7.

\subsubsection{The specific energy to liquefaction of a partially saturated soil}

A partially saturated soil is a three-phase thermodynamic system. In order to analyse the results in this framework, it is necessary to introduce some hypothesis. In this case it is assumed that the process is isothermal (i.e. no heat is generated or lost during the test), the system has a constant mass (i.e. no increase or decrease of the mass of air, water or soil in the specimen during the test), and it is thermodynamically open (i.e. within the specimen the deformation process implies internal flows of air and water). Furthermore, pore air can be treated as an ideal gas.

The total specific (i.e. referred to a unit reference volume, therefore to be measured in $\mathrm{J} / \mathrm{m}^{3}$ or $\mathrm{Pa}$ ) energy of deformation $\mathrm{E}_{\text {tot, }}$ needed to reach liquefaction in such a system can be seen as the sum of three components: the first one represents the work done by the deformation of the soil skeleton, the other two are related to the work caused by the flow of mass of water and air into the system of pores. $E_{\text {tot }}$ can be expressed as:

$$
E_{\text {tot }}=E_{s k}+E_{w}+E_{\text {air }}
$$

8.

where $E_{s k}, E_{w}$ and $E_{\text {air }}$ are the energies of deformation of soil skeleton, water and air. The term $E_{\text {sk }}$ (energy of the soil skeleton) is composed by two components: the volumetric and the deviatoric part. In the following, the volumetric part will be called $\mathrm{E}_{\mathrm{v}}$ because it is connected to the change in volume, while the deviatoric one is $E_{s}$, connected with the distorsional strain $\varepsilon_{s}$ :

$$
E_{s k}=E_{v, s k}+E_{s, s k}
$$


9.

In this paper, Equation 8 will be used with reference to undrained tests, and therefore the term $E_{v, s k}$ differs from zero only for the unsaturated specimens.

Equation 8 can be formally rewritten by using the Helmholtz function $\psi$. In fact, the gradient $d \psi$ represents the portion of the internal energy that is free for doing work at a constant temperature (Li, 2007). Therefore, considering also Equation 8, it assumes the form:

$$
d \psi=\left[\left(\sigma-u_{a} \delta\right)+s S_{r} \delta\right]: d \varepsilon-\frac{e}{1+e} s d S_{r}+\frac{e_{0}}{1+e_{0}}\left(1-S_{r, 0}\right) u_{a} d\left(\ln \rho_{a}\right)
$$

10.

where the incremental dissipations are neglected. In Equation 10 the term $\left(\boldsymbol{\sigma}-u_{a} \mathbf{\delta}\right)$ is the net stress, $u_{a}$ is the pore air pressure, $s$ is the suction, $S_{r}$ is the degree of saturation, $e$ is the void ratio of the soil and $\rho_{a}$ is the mass density of the air.

Considering the average curve of volumetric deformations (as shown for instance in Figure 15(a)), and using Equation 9, $E_{v}$ and $E_{s}$ in eq. (8) can be evaluated as:

$$
E_{v, s k}=\int_{0}^{\varepsilon_{v, l i q}}\left[\left(\sigma-u_{a}+s S_{r}\right)\right] \cdot d \varepsilon_{v}
$$

11.

$$
E_{s, s k}=\iint_{D} d q d \varepsilon_{s}
$$

12.

$\mathrm{E}_{\mathrm{v}, \mathrm{sk}}$ does not depend on CSR or Nliq, depending only on the stress state $\sigma^{\prime}\left(\mathrm{S}_{\mathrm{r}}\right)$, on the initial void ratio $e_{0}$ (ruling the shape of the $\sigma^{\prime}: \varepsilon_{v}$ relationship), and apparently on the void ratio at 
liquefaction (to which $\varepsilon_{v, \text { liq }}$ is related). However, as shown by Figure 16 , the value of $\varepsilon_{v}$,liq is univocally related to $\sigma^{\prime}\left(\mathrm{S}_{r}\right)$ and $e_{0}$, regardless of the applied CSR (i.e. $\varepsilon V=\varepsilon v\left(\sigma^{\prime}\right.$, e e). Therefore, $E_{v, s k}=f\left(\sigma^{\prime}\left(S_{r}\right), e_{0}\right)$.

$E_{s, s k}$ (equation 12) can be seen as the sum of the areas of all the cycles in the $\varepsilon s: q$ plane (D in Figure 17) up to liquefaction (defined in terms of strains). Therefore, it is strictly related to the applied CSR.

The energy of deformation of water is:

$$
E_{w}=-\int_{S_{r 0}}^{S_{r, \text { liq }}} \frac{e\left(S_{r}\right)}{1+e\left(S_{r}\right)} s\left(S_{r}\right) \cdot d S_{r}
$$

13.

and is due to the change of water content. Since the small cyclic variations of $S_{r}$ along the deformation process would make the calculation cumbersome, a simplification has been introduced in solving eq. (13), considering a constant (average) value of s. Such a simplification has no effect, since the variation of $s$ along the tests was always very low. Equation 13 can be seen as the energetic contribution of the water content change, being $E_{w}$ proportional to the integral of the water retention curve starting from a given initial degree of saturation Sro. Finally, the energy of deformation of air can be evaluated as:

$E_{a i r}=\frac{e_{0}}{1+e_{0}}\left(1-S_{r, 0}\right) u_{a, l i q} d\left(\ln \rho_{a, l i q}\right)$

14.

This contribution describes the effect of pressure variation in the gas phase. 
In order to analyse and interpret into a unique framework the available experimental data, Equation 8 has been written as:

$E_{t o t, l i q}=E_{v, l i q}+E_{s, l i q}$

15.

Where $E_{s, l i q}$ is the deviatoric energy at liquefaction, while $E_{v, l i q}$ is the sum of all the volumetric components (Equations 11, 13 and 14) of the total specific energy $E_{\text {tot,liq }}$ needed to reach liquefaction:

$E_{v, l i q}=E_{v, s k}+E_{w}+E_{a i r}$

16.

$E_{v, \text { liq }}$ is a function of the initial values of the effective stress, of the void ratio and of the degree of saturation $\left(E_{v, l i q}=E_{v, l i q}\left(\sigma^{\prime} 0, e_{0}, S_{0}\right)\right)$. In such a way, it may be seen as a synthetic state variable ruling the liquefaction resistance of a given soil. In other words, in the plane CRR-N $\mathrm{N}_{\text {liq, }}$, for a given soil, each liquefaction resistance curve is expected to be univocally identified by the initial values of $\sigma_{0}^{\prime}, e_{0}$ and $\mathrm{Sr}_{0}$.

In order to verify such a conclusion, all the components of the specific volumetric energy were evaluated for the three tested materials (SAS sand, Bauxite, and Inagi sand), using Equations 11, 13 and 14. The average curves of Figure 16(a) were used to evaluate $E_{v, s k}$ using Equation 11. Table 7 reports for all tests and materials the different energy components.

The data reported in Table 7 are also plotted in Figure 18, along with the best fitting cyclic

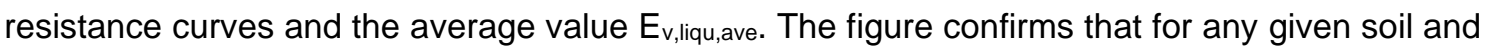
any given initial state (i.e. any given set of $\sigma^{\prime} 0, e_{0}, S_{r}$ ) the cyclic resistance curve is related to a unique value of the volumetric component $E_{\mathrm{v}, \text { liq }}$ of the specific energy. 
The same results are then reported in the normalized plot shown in Figure 19. The best fitting of the experimental results was obtained in this normalized plane using the equation:

$$
\frac{C R R}{\sqrt{E_{v, l i q}}}=-0.024 \cdot \ln \left(N_{l i q}\right)+0.2846
$$

17.

In which $E_{\mathrm{v}, \text { liq }}$ is expressed in $\mathrm{kPa}$. Equation 17 is intriguing as it takes into account all the relevant state variables $\left(e_{0}, \sigma^{\prime} u n, S_{r}\right)$. However, it must be stressed out that the tests reported in this paper were carried out with a limited range of void ratios and confining stresses. So, the possibility to consider Equation 17 as a general law ruling the liquefaction resistance of unsaturated soils must be confirmed by comparing it with the results obtained with a wider range of state variables. At this stage, it can be considered only as a law referred to loose unsaturated sands for a given confining stress $(50 \mathrm{kPa})$. Further research is needed to generalize these results.

A further confirmation of the relevance of $E_{v, \text { liq }}$ to identify liquefaction resistance is highlighted in figure 20. In this figure, the dependency of $L R R_{15}$ on the volumetric specific energy $E_{v}$ is clear for all the tested materials. If confirmed by further experiments on other soils, other densities and other confining stresses, this may therefore be considered as a simple tool to predict the increment of cyclic resistance due to desaturation, as compared to the cyclic resistance of the saturated soil.

\section{Conclusions}

The experimental results reported in this paper have confirmed that desaturation increases liquefaction resistance, and have also helped in better understanding the change of behaviour of the soil, after liquefaction is triggered, through the definition of an apparent viscosity. The interpretation of the experimental results has shown that the transition from the soil-like to the fluid-like behaviour is not immediate, and some cycles are needed to this aim. A link seems to 
exist between the values of the apparent viscosity defining the different behaviours and the coefficient of uniformity of the soils: the more graded the material, and therefore the higher the energy dissipation because of particles relative movements, the higher the values of the apparent viscosity.

The energetic interpretation reported in the final part of the paper stems from the experimental observation that, for a soil having given values of void ratio, degree of saturation and confining stress, undrained cyclic tests lead to a unique value of the final volumetric deformation, regardless of the applied deviatoric stress. The theoretical interpretation has led to the conclusion that this is consistent with the assumption that the cyclic resistance curve of unsaturated soils is a unique function of the volumetric component of the total specific energy spent to reach liquefaction. Further investigation is needed to confirm these conclusions. From a modelling point of view, however, this seems extremely promising as it may lead to new and more general approaches to define the cyclic resistance of unsaturated sandy soils.

\section{Acknowledgements}

This work was carried out as part of the European project Horizon 2020 - Assessment and Mitigation of liquefaction potential across Europe: A holistic approach to protect structures infrastructures for improved resilience to earthquake - induced liquefaction disasters "LIQUEFACT" (grant agreement No. 700748).

\section{References}

Bishop A. W. and Blight G. E. (1963) Some aspects of effective stress in saturated and partly saturated soils. Gèotechnique, 13(3): 177-197.

Chaney R. (1978) Saturation effects on the cyclic strength of sands. Proc., ASCE Special Conf. on Earthquake Engineering and Soil Dynamics, New York, 342-358.

Chen G., Zhou E., Wang Z., Wang B., Li X. (2016) Experimental study on fluid characteristics of medium dense saturated fine sand in pre- and post-liquefaction. Bulletin of Earthquake Engineering 14(8): 2185-2212. 
Eseller-Bayat E., Yegian MK., Alshawabkeh A., Gokyer (2012) Prevention of liquefaction during earthquakes through induced partial saturation in sands. Geotechnical engineering: new horizons. IOS Press, Amsterdam, 188-194.

Gallipoli D., Gensa A., Vanet J. and Romero E. (2002). Role of degree of saturation on the normally consolidated behavior of unsaturated soils. Proc. 3rd Int. Conf. on Unsaturated Soils, 115-120.

Gallipoli D., Gens A., Sharma R., Vaunat, J. (2003) An elastoplastic model for unsaturated soil incorporating the effects of suction and degree of saturation on mechanical behaviour. Gèotechnique 53(1): 123-135

Ishihara K., Tsukamoto Y., Nakazawa H., Kamada K., and Huang Y. (2002) Resistance of partly saturated sand to liquefaction with reference to longitudinal and shear wave velocities. Soil Foundation., 42(6): 93-105.

Li X.S. (2007) Thermodynamics-based constitutive framework for unsaturated soils. 1:Theory. Gèotechnique 57(5): 411-422.

Nishimura T., Koseki J., Fredlund D.G., Rahardjo H., (2012) Micro-porous membrane technology for measurement of soil-water characteristic curve. Geotech. Test. J 35, 201208.

Okamura M. and Soga Y. (2006) Effects of pore fluid compressibility on liquefaction resistance of partially saturated sand. Soils and Foundations 46: 695-700.

Tatsuoka F., Toki S., Miura S., Kato H., Okamoto M., Yamada S., Yasuda S., Tanizawa F. (1986). Some factors affecting cyclic undrained triaxial strength of sand. Soils Found. 26 (3): $99-116$.

Tsukamoto Y., Kawabe S., Matsumoto J., Hagiwara S., (2014) Cyclic resistance of two unsaturated silty sands against soil liquefaction. Soils Found. 54 (6): 1094-1103.

Vanapalli S. K., Fredlund D. G., Pufahl D. E. and Clifton A. W. (1996) Model for the prediction of shear strength with respect to soil suction. Canadian Geotechnical Journal 33(3): 379-392.

Wang H., Koseki J., Sato T., Chiaro G., and Tan Tian J. (2016a) Effect of saturation on liquefaction resistance of iron ore fines and two sandy soils. Soils and Foundations 56(4): $732-744$ 
Wang H., Sato T., Koseki J., Chiaro G., Tan Tian J. (2016b) A system to measure volume change of unsaturated soils in undrained cyclic triaxial tests. Geotechnical Testing Journal.39(4): 532-542.

Wheeler S. J., Sharma R. S., Bulsson M. S. R. (2003) Coupling of hydraulic hysteresis and stress-strain behavior in unsaturated soils. Gèotechnique 53(1): 41-54.

Yegian M. K., Eseller-Bayat E., Alshawabkeh A. and Ali S. (2007) Induced-Partial Saturation for liquefaction mitigation: experimental investigation. Journal of geotechnical and geoenviromental engineering ASCE 133(4): 372-380.

Yoshimi Y., Yanaka K., and Tokimatsu K., (1989) Liquefaction resistance of partially saturated sand. Soils Found., 29(2): 157-162.

Tables

Table 1. Material Properties of the Soils

\begin{tabular}{c|c|c|c}
\hline Material Property & $\begin{array}{c}\text { Sant'Agostino } \\
\text { Sand }\end{array}$ & Bauxite & Inagi Sand \\
\hline Fines Content $(<0.075 \mathrm{~mm})$ & 20.0 & 40.6 & 29.5 \\
(\%) & 2.674 & 2.642 & 2.656 \\
Specific Gravity, Gs & 0.200 & 0.200 & 0.115 \\
D50 $_{5 m}(\mathrm{~mm})$ & 1.01 & - & 1.645 \\
$\mathrm{e}_{\max }$ & 0.37 & - & 0.907 \\
$\mathrm{e}_{\min }$ &
\end{tabular}

Table 2. Cyclic triaxial tests carried out on saturated soil

\begin{tabular}{ccccc}
\hline Test & $\sigma_{c}^{\prime}(\mathrm{kPa})$ & $\mathrm{e}^{*}$ & $\mathrm{Dr}^{*}(\%)$ & $\mathrm{CSR}$ \\
\hline S_SA1 & 50 & 0.707 & 47 & 0.147 \\
S_SA2 & 51 & 0.738 & 43 & 0.128 \\
S_SA3 & 51 & 0.719 & 46 & 0.098 \\
S_SA4 & 51 & 0.713 & 47 & 0.087 \\
S_SAJ*** & 51 & 0.730 & 44 & 0.092 \\
\hline S_SA5 & 51 & 0.604 & 64 & 0.179 \\
S_SA6 & 51 & 0.636 & 59 & 0.147 \\
S_SA7 & 51 & 0.652 & 56 & 0.128 \\
\hline S_BA1 & 49 & 0.857 & $84^{* *}$ & 0.181 \\
S_BA2 & 49 & 0.839 & $85^{* *}$ & 0.173 \\
S_BA3 & 49 & 0.891 & $82^{* *}$ & 0.163 \\
\hline S_IN1 & 59 & 1.194 & 62 & 0.160 \\
S_IN2 & 58 & 1.179 & 64 & 0.142 \\
\hline \multicolumn{2}{r}{${ }^{*}$ relative density and void ratio after consolidation phase } \\
${ }^{* *}$ Degree of Compaction Values ${ }^{* * *}$ Test carried out in Japanese Triaxial cell
\end{tabular}


Table 3. Cyclic triaxial tests carried out on unsaturated soil

\begin{tabular}{ccccccc}
\hline Test & $\sigma_{\text {un }}^{\prime}(\mathrm{kPa})$ & $\mathrm{e}^{*}$ & $\mathrm{Dr}^{*}(\%)$ & $\mathrm{Sr}^{*}(\%)$ & Sraverage $\left.^{*} \%\right)$ & CSR \\
\hline U_SA1 & 49.5 & 0.710 & 48 & 53.0 & \multirow{2}{*}{55.0} & 0.370 \\
U_SA2 & 50.5 & 0.670 & 53 & 54.0 & & 0.348 \\
U_SA3 & 48.9 & 0.670 & 54 & 56.0 & & 0.307 \\
\hline U_SA4 & 50.5 & 0.610 & 63 & 90.0 & & 0.160 \\
U_SA5 & 49.8 & 0.600 & 64 & 81.5 & & 0.222 \\
U_SA6 & 49.8 & 0.590 & 66 & 87.2 & \multirow{2}{*}{87.0} & 0.254 \\
U_SA7 & 49.9 & 0.580 & 67 & 86.7 & & 0.223 \\
U_SA8 & 48.8 & 0.590 & 66 & 87.6 & & 0.258 \\
U_SA9 & 50.4 & 0.610 & 62 & 88.5 & & 0.297 \\
\hline U_BA1 & 51.9 & 0.910 & $79^{* *}$ & 58.0 & & 0.353 \\
U_BA2 & 56.3 & 0.920 & $79^{* *}$ & 56.0 & \multirow{2}{*}{56.7} & 0.361 \\
U_BA3 & 51.8 & 0.940 & $78^{* *}$ & 56.0 & & 0.398 \\
\hline U_BA4 & 49.8 & 0.760 & $88^{* *}$ & 84.0 & \multirow{2}{*}{84.5} & 0.322 \\
U_BA5 & 49.1 & 0.750 & $85^{* *}$ & 85.0 & & 0.279 \\
\hline U_IN1 & 62.2 & 1.200 & 60 & 49.0 & & 0.393 \\
U_IN2 & 64.2 & 1.220 & 58 & 48.0 & 49.7 & 0.377 \\
U_IN3 & 62.3 & 1.140 & 69 & 52.0 & & 0.404 \\
\hline
\end{tabular}

${ }^{*}$ relative density, void ratio and degree of saturation after consolidation phase; ${ }^{* *}$ Degree of Compaction values;

Table 4. Results of cyclic saturated tests

\begin{tabular}{cccccc}
\hline Test & $\begin{array}{c}\sigma_{C}^{\prime} \\
(\mathrm{kPa})\end{array}$ & $\begin{array}{c}\mathrm{Dr}^{*} \\
(\%)\end{array}$ & CSR & $\begin{array}{c}N_{\text {liq }} \\
\left(\varepsilon_{\mathrm{DA} A}=5 \%\right)\end{array}$ & $\begin{array}{c}N_{\text {liq }} \\
(\mathrm{Ru}=0.9)\end{array}$ \\
\hline S_SA1 & 50 & 47 & 0.147 & 2.7 & 3 \\
S_SA2 & 51 & 43 & 0.128 & 7.5 & 7 \\
S_SA3 & 51 & 46 & 0.098 & 19 & 19 \\
S_SA4 & 51 & 47 & 0.087 & No & No \\
S_SAJ*** & 51 & 44 & 0.092 & 53 & 53 \\
S_SA5 & 51 & 64 & 0.179 & 3 & 3 \\
S_SA6 & 51 & 59 & 0.147 & 13 & 11.5 \\
S_SA7 & 51 & 56 & 0.128 & 15.5 & 14 \\
\hline S_BA1 & 49 & $84^{* *}$ & 0.181 & 6.4 & 7.6 \\
S_BA2 & 49 & $85^{* *}$ & 0.173 & 12.3 & 13.0 \\
S_BA3 & 49 & $82^{* *}$ & 0.163 & 22.9 & 23.0 \\
\hline S_IN1 & 59 & 62 & 0.160 & 8.7 & 9.2 \\
S_IN2 & 58 & 64 & 0.142 & 48.4 & 50.8 \\
\hline
\end{tabular}

*relative density and degree of saturation after consolidation phase ${ }^{* *}$ Degree of Compaction values ***Test carried out in Japanese Triaxial cell

Table 5. Results of all cyclic unsaturated triaxial tests.

\begin{tabular}{|c|c|c|c|c|c|c|c|}
\hline Test & $\begin{array}{c}\sigma^{\prime} \text { un } \\
(\mathrm{kPa})\end{array}$ & $\begin{array}{l}\mathrm{Dr}^{*} \\
(\%)\end{array}$ & $\begin{array}{l}\mathrm{Sr}^{*} \\
(\%)\end{array}$ & $\begin{array}{c}\text { Sraverage } \\
(\%)\end{array}$ & CSR & $\begin{array}{c}\text { Nliq } \\
(\varepsilon \mathrm{DA}=5 \%)\end{array}$ & $\begin{array}{c}N_{\text {liq }} \\
(R u=0.9)\end{array}$ \\
\hline U_SA1 & 49.6 & 48 & 53.0 & \multirow{3}{*}{55.0} & 0.370 & 3.6 & 11.2 \\
\hline U_SA2 & 50.5 & 53 & 54.0 & & 0.348 & 6.1 & 18 \\
\hline U_SA3 & 48.9 & 54 & 56.0 & & 0.307 & 26 & 34 \\
\hline U_SA4 & 50.5 & 63 & 90.0 & \multirow{6}{*}{87.0} & 0.160 & 201 & 202 \\
\hline U_SA5 & 49.8 & 64 & 81.5 & & 0.222 & 35.3 & 36 \\
\hline U_SA6 & 49.8 & 66 & 87.2 & & 0.254 & 11.3 & - \\
\hline U_SA7 & 49.9 & 67 & 86.7 & & 0.223 & 24.4 & 25 \\
\hline U_SA8 & 48.8 & 66 & 87.6 & & 0.258 & 9.6 & 10.5 \\
\hline U_SA9 & 50.4 & 62 & 88.5 & & 0.297 & 2.1 & 3 \\
\hline U_BA1 & 51.9 & $79^{\star *}$ & 58.0 & \multirow{3}{*}{56.7} & 0.353 & 113.2 & 150 \\
\hline$U_{-}^{-} \mathrm{BA} 2$ & 56.3 & $79^{* *}$ & 56.0 & & 0.361 & 37.3 & 77.8 \\
\hline U_BA3 & 51.8 & $78^{* *}$ & 56.0 & & 0.398 & 12.6 & 58 \\
\hline
\end{tabular}




\begin{tabular}{cccccccc}
\hline U_BA4 & 49.8 & $88^{\star \star}$ & 84.0 & \multirow{2}{*}{84.5} & 0.322 & 0.8 & 3 \\
U_BA5 & 49.1 & $85^{\star *}$ & 85.0 & & 0.279 & 8.3 & 22 \\
\hline U_IN1 & 62.2 & 60 & 49.0 & \multirow{2}{*}{49.7} & 0.393 & 13.9 & - \\
U_IN2 & 64.2 & 58 & 48.0 & \multirow{2}{*}{49.7} & 0.377 & 49.6 & - \\
U_IN3 & 62.3 & 69 & 52.0 & & 0.404 & 8.6 & 32 \\
\hline
\end{tabular}

${ }^{*}$ relative density and degree of saturation after consolidation phase ${ }^{\star *}$ Degree of Compaction values

Table 6. Apparent viscosity for each material.

\begin{tabular}{|c|c|c|c|c|c|}
\hline & $\begin{array}{c}\text { SAS } \\
(\mathrm{Sr} \approx 55 \%)\end{array}$ & $\begin{array}{c}\text { SAS } \\
(\mathrm{Sr} \approx 87 \%)\end{array}$ & $\begin{array}{c}\text { Baux } \\
(\mathrm{Sr} \approx 57 \%)\end{array}$ & $\begin{array}{c}\text { Baux } \\
(\mathrm{Sr} \approx 84.5 \%)\end{array}$ & $\begin{array}{c}\text { Inagi } \\
(\mathrm{S} r \approx 50 \%)\end{array}$ \\
\hline$U_{c}$ & \multicolumn{2}{|c|}{16.7} & \multicolumn{2}{|c|}{400.0} & 30.0 \\
\hline$\eta_{\text {trans }}(\mathrm{kPa} \cdot \mathrm{s})$ & $1000 \div 3000$ & $1000 \div 3000$ & 8000 & 8000 & 3000 \\
\hline$\eta_{5 \%}(\mathrm{kPa} \cdot \mathrm{s})$ & 963.4 & 1241.9 & 1406.2 & 1235.5 & 1375.7 \\
\hline$\eta_{\text {fluid }}(\mathrm{kPa} \cdot \mathrm{s})$ & 100 & 70 & 400 & 200 & $100 \div 300$ \\
\hline
\end{tabular}

Table 7. Energies of tests

\begin{tabular}{cccccccccc}
\hline Test & Material & $\begin{array}{c}\sigma^{\prime} \text { un } \\
(\mathrm{kPa})\end{array}$ & $\mathrm{e}$ & $\begin{array}{c}\mathrm{Sr} \\
(\%)\end{array}$ & $\begin{array}{c}\mathrm{E}_{\mathrm{v}, \mathrm{sk}} \\
(\mathrm{kPa})\end{array}$ & $\begin{array}{c}\mathrm{E}_{\mathrm{w}} \\
(\mathrm{kPa})\end{array}$ & $\begin{array}{c}E_{\text {air }} \\
(\mathrm{kPa})\end{array}$ & $\begin{array}{c}\mathrm{E}_{\mathrm{v}, \text { liq }} \\
(\mathrm{kPa})\end{array}$ & $\begin{array}{c}\mathrm{E}_{\mathrm{v}, \text { liq,ave }} \\
(\mathrm{kPa})\end{array}$ \\
\hline U_SA1 & SAS & 49.6 & 0.71 & 53.0 & 1.7 & 0 & 0.57 & 2.27 & \\
U_SA2 & SAS & 50.5 & 0.67 & 54.0 & 1.7 & -0.040 & 0.57 & 2.23 & 2.28 \\
U_SA3 & SAS & 48.9 & 0.67 & 56.0 & 1.7 & -0.020 & 0.65 & 2.33 & \\
\hline U_SA4 & SAS & 50.5 & 0.61 & 90.0 & 1.1 & 0 & 0.10 & 1.23 & \\
U_SA5 & SAS & 49.8 & 0.60 & 81.5 & 1.1 & 0 & 0.21 & 1.31 & \\
U_SA6 & SAS & 49.8 & 0.59 & 87.2 & 1.1 & 0 & 0.05 & 1.15 & 1.19 \\
U_SA7 & SAS & 49.9 & 0.58 & 86.7 & 1.1 & 0 & 0.15 & 1.23 & \\
U_SA8 & SAS & 48.8 & 0.59 & 87.6 & 1.1 & 0 & 0.05 & 1.15 & \\
U_SA9 & SAS & 50.4 & 0.61 & 88.5 & 1.1 & 0 & 0.03 & 1.13 & \\
\hline U_BA1 & Bauxite & 51.9 & 0.91 & 58.0 & 2.3 & -0.138 & 1.10 & 3.26 & \\
U_BA2 & Bauxite & 56.3 & 0.92 & 56.0 & 2.3 & -0.167 & 1.00 & 3.13 & 3.05 \\
U_BA3 & Bauxite & 51.8 & 0.94 & 56.0 & 2.3 & -0.109 & 0.57 & 2.76 & \\
\hline U_BA4 & Bauxite & 49.8 & 0.76 & 84.0 & 0.93 & 0.106 & 0.09 & 1.16 & 1.20 \\
U_BA5 & Bauxite & 49.1 & 0.75 & 85.0 & 0.93 & 0.127 & 0.16 & 1.23 & 1.20 \\
\hline U_IN1 & Inagi & 62.2 & 1.20 & 49.0 & 3.4 & -0.581 & 1.14 & 3.96 & \\
U_IN2 & Inagi & 64.2 & 1.22 & 48.0 & 3.4 & -0.655 & 1.32 & 4.06 & 3.98 \\
U_IN3 & Inagi & 62.3 & 1.14 & 52.0 & 3.4 & -0.661 & 1.18 & 3.92 & \\
\hline
\end{tabular}

\section{Figures}




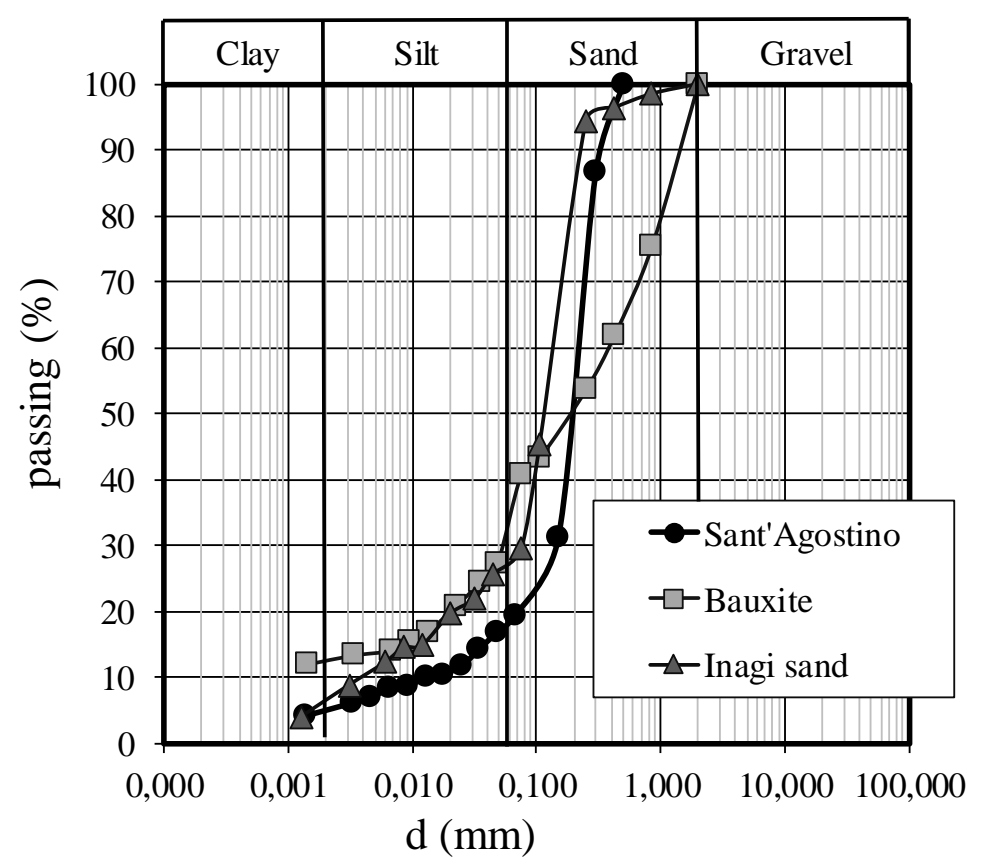

Figure 1. Grain size distribution of Soils.

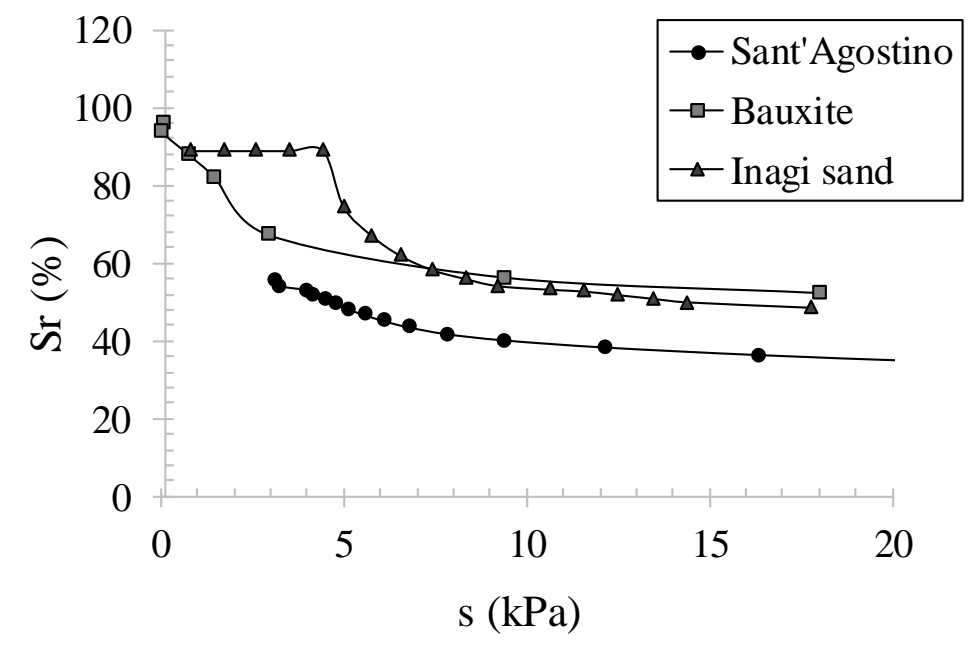

Figure 2. Soil-Water Retention Curve (SWRC) of Soils. 


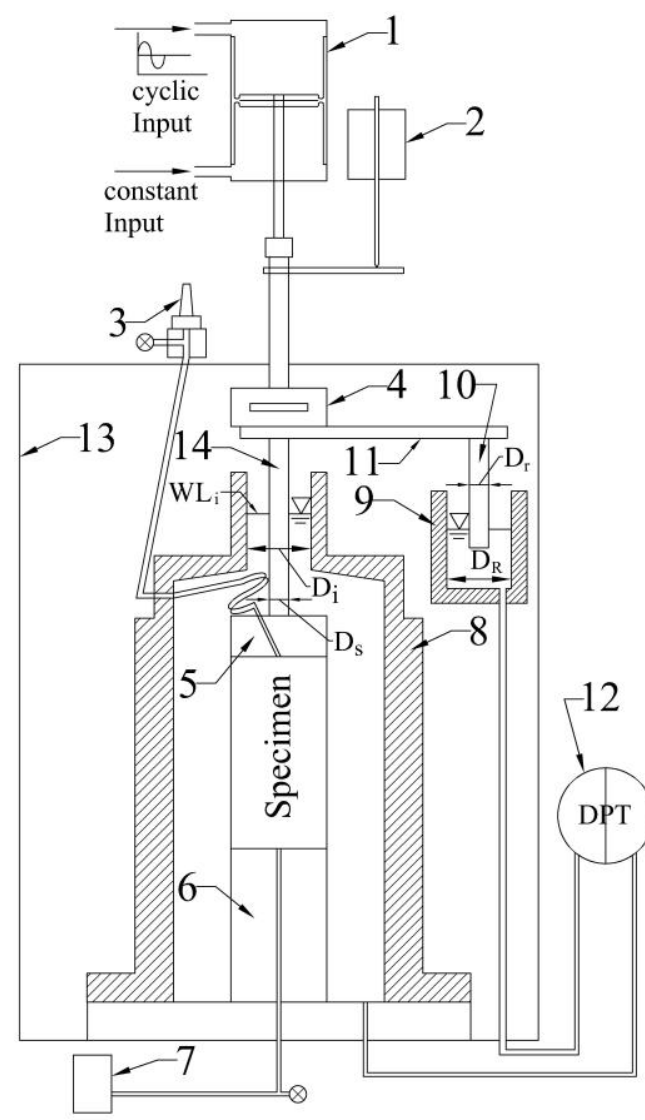

1. Double action cylinder

2. VDT

3. Pore air pressure transducer

4. Load cell

5. Top cap

6. Pedestal

7. Pore water pressure transducer

8. Inner cell

9. Reference tube

10. Linkage acrylic rod

11. Aluminum plate

12. DPT

13. Pressure cell

14. Stainless steel loading shaft

$\mathrm{D}_{\mathrm{s}}$ : Diameter of loading shaft

$D_{r}:$ Diameter of linkage rod

$\mathrm{D}_{\mathrm{R}}$ : Inner diameter of reference tube

$D_{i}$ : Inner diameter of upper part of inner cell

$\mathrm{D}_{\mathrm{s}}=\mathrm{D}_{\mathrm{r}} ; \mathrm{D}_{\mathrm{R}}=\mathrm{D}_{\mathrm{i}}$

$\mathrm{WL}_{\mathrm{i}}$ : Water level in the inner cell

Figure 3. Scheme of the Triaxial Japanese cell (low degree of saturation) (Wang et al.2016b).

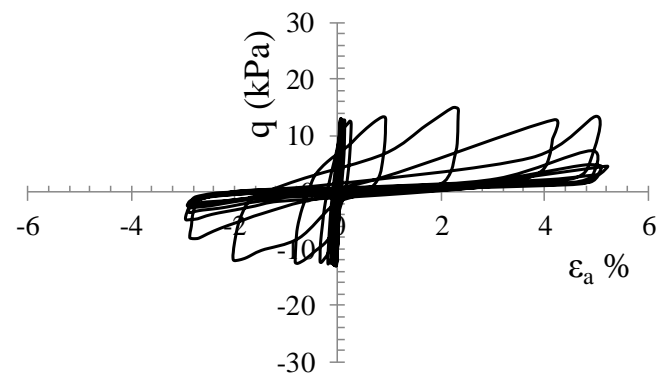

(a)

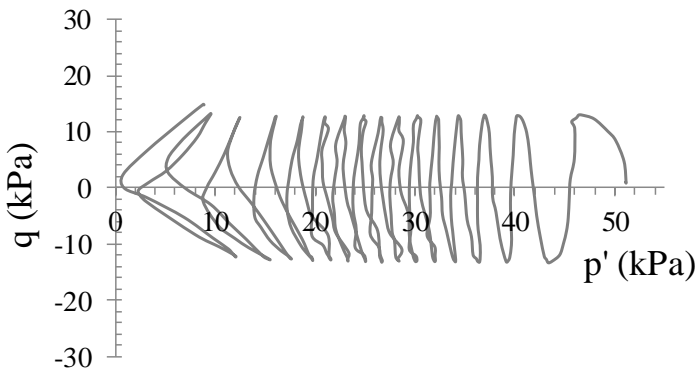

(c)

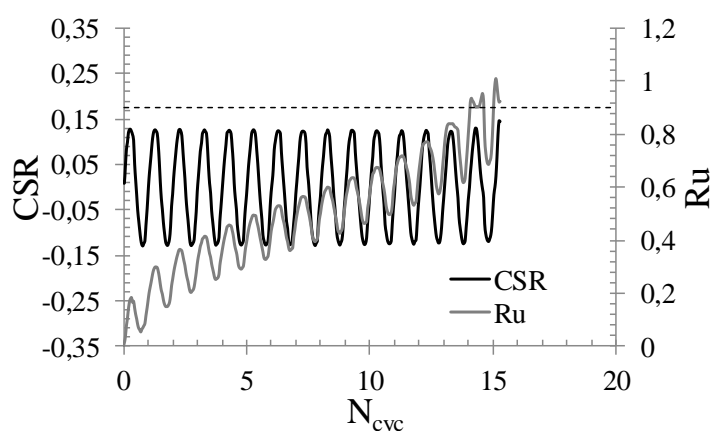

(b)

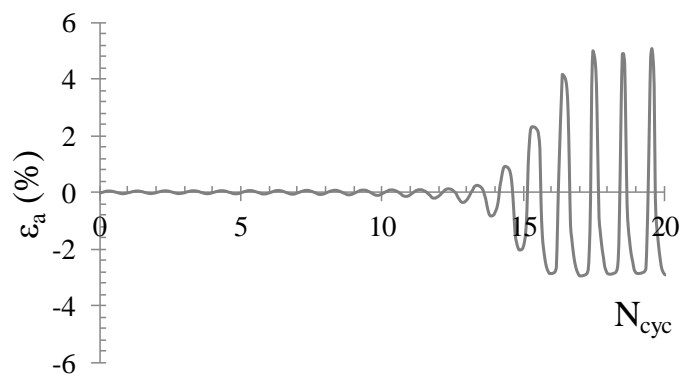

(d)

Figure 4 (a, b, c, d). Results of a cyclic triaxial test (S_SA7). 


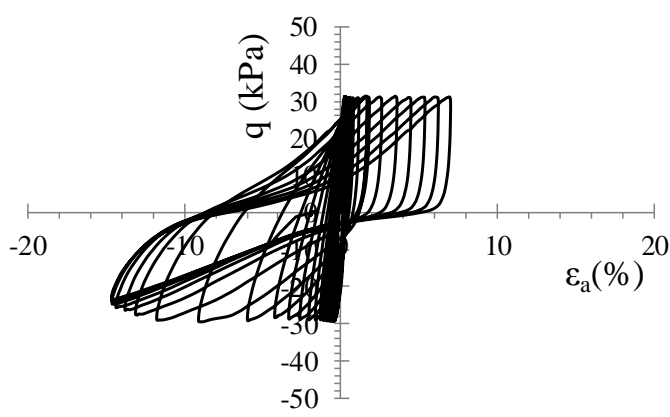

(a)

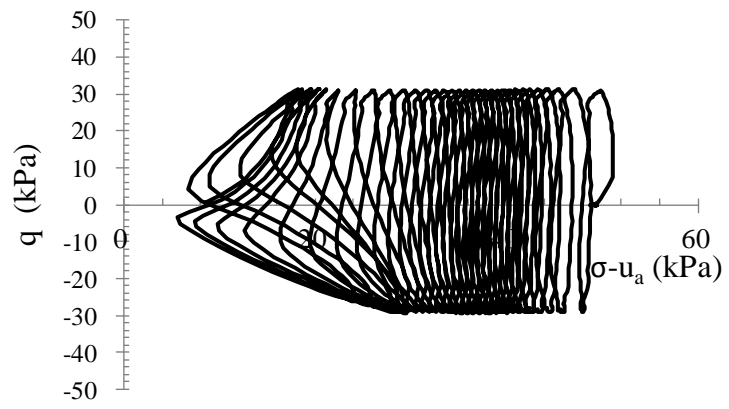

(c)

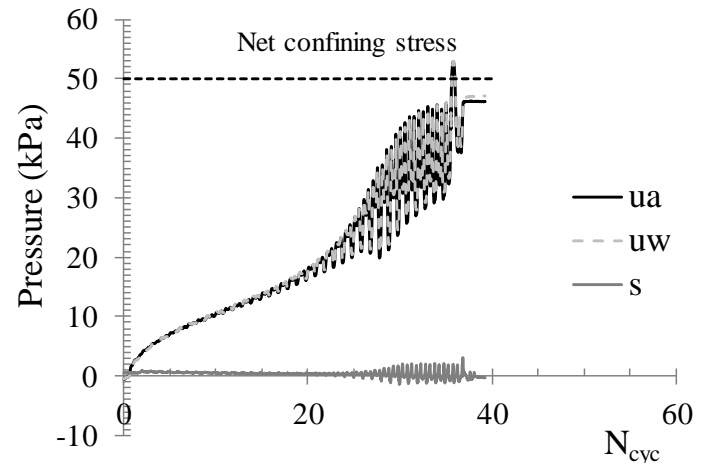

(b)

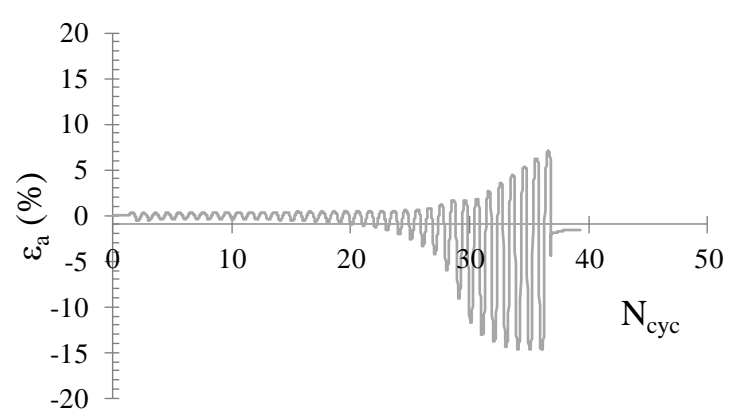

(d)

Figure 5 (a, b, c, d). Results of a cyclic triaxial test (U_SA3).

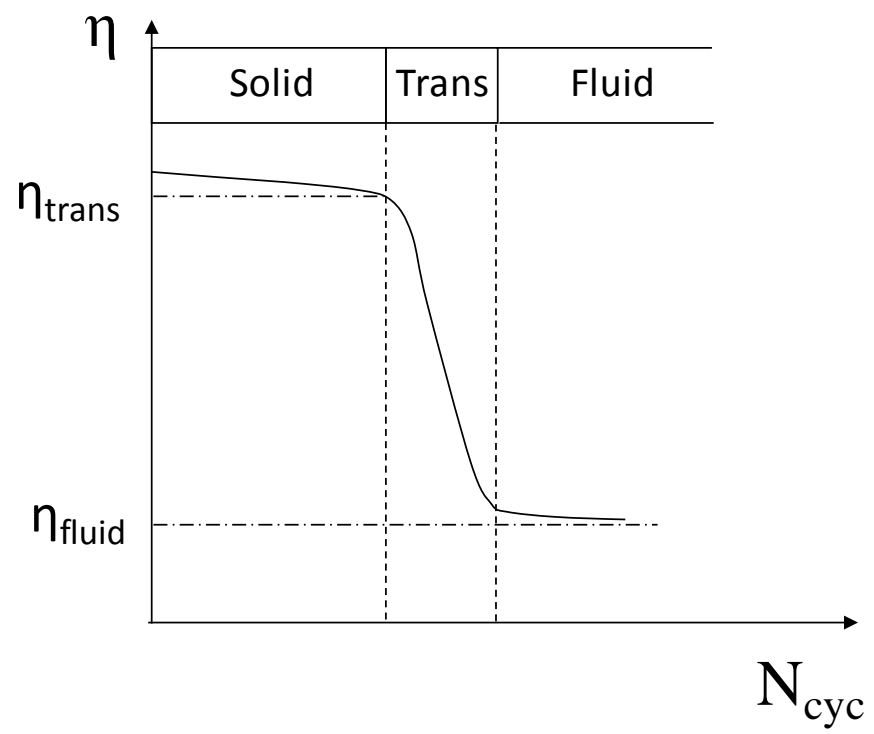

Figure 6. Sketch of the expected trend of the apparent viscosity $\eta$ with the number of cycles, $\mathrm{N}_{\text {cyc. }}$. 


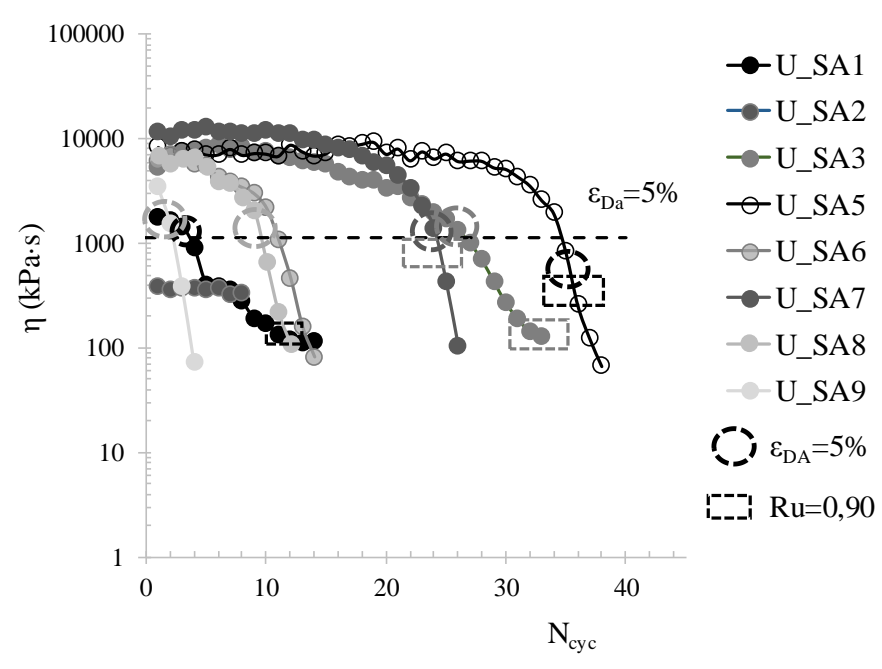

(a)

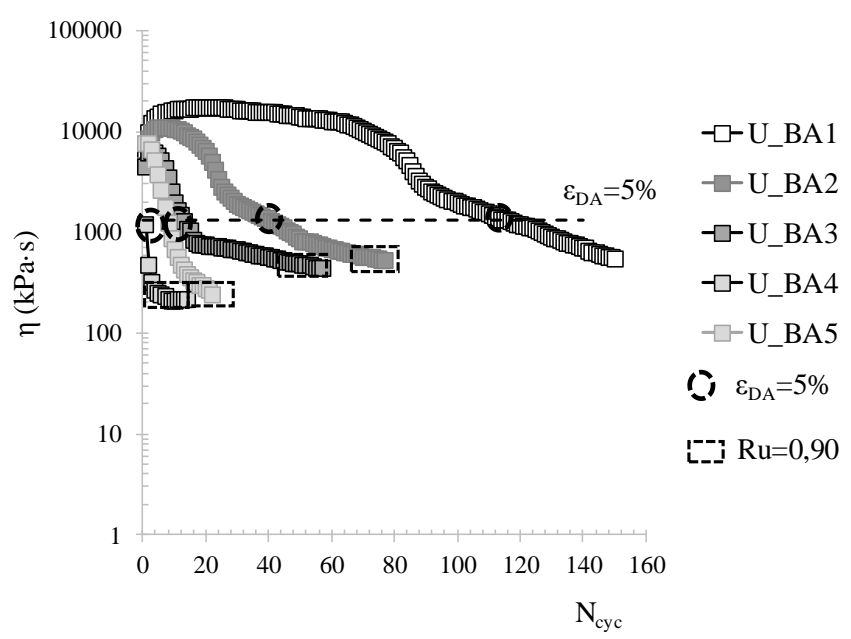

(b)

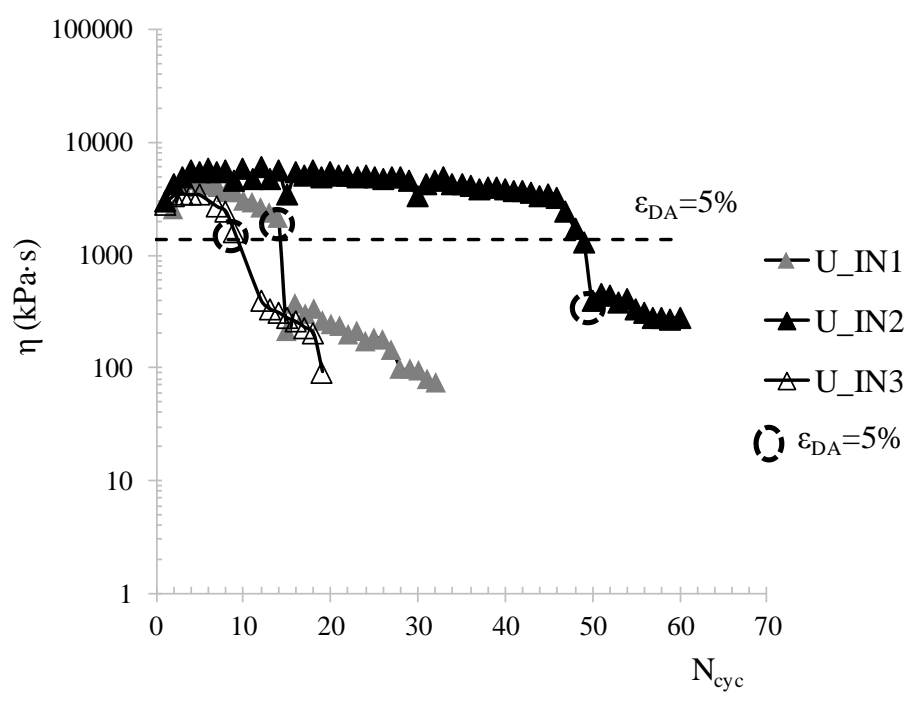

(c) 
Figure 7. Apparent viscosity $\eta$ versus $\mathrm{N}_{\text {cyc }}$ for SAS (a), Bauxite (b) and Inagi sand (c), with the indication of the points for which liquefaction was attained, as defined in terms of either $R u=0.9$ or $\varepsilon D A=5 \%$.

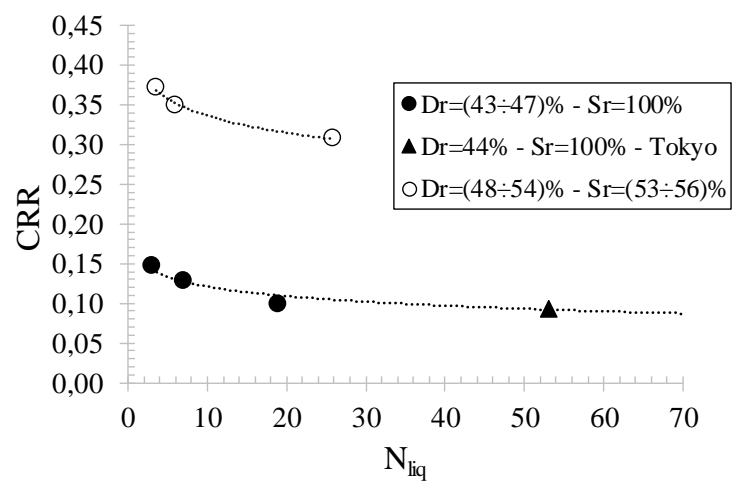

(a)

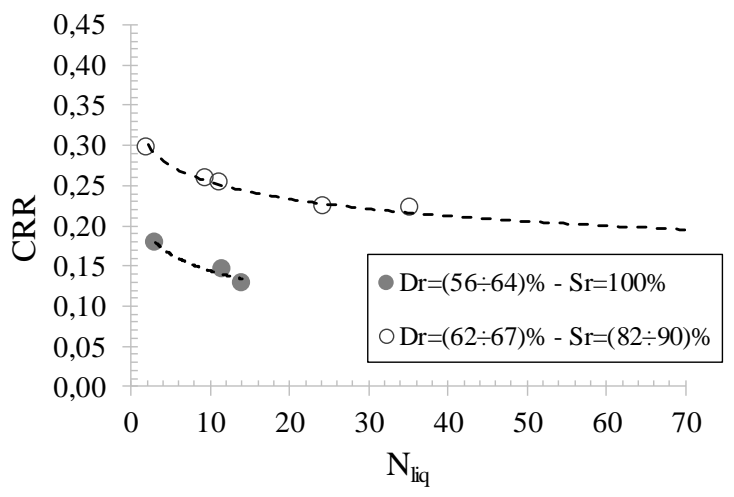

(b)

Figure $8(a, b)$. Cyclic resistance curves for SAS.

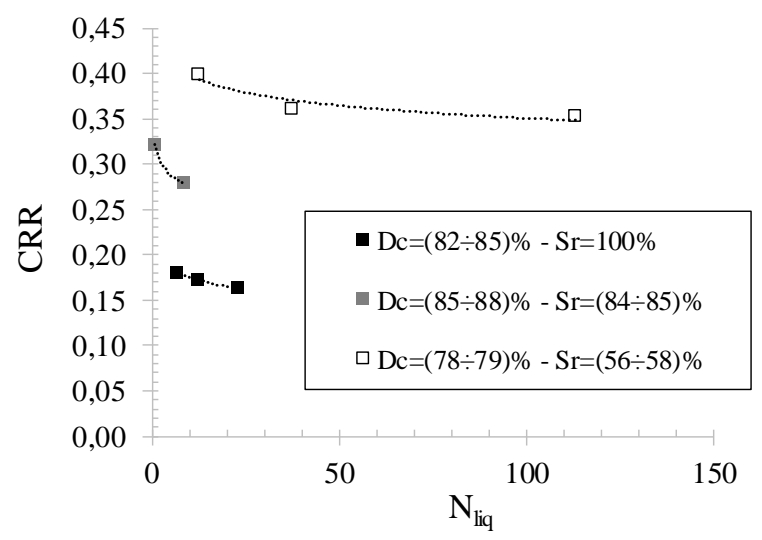

Figure 9. Cyclic resistance curves for Bauxite.

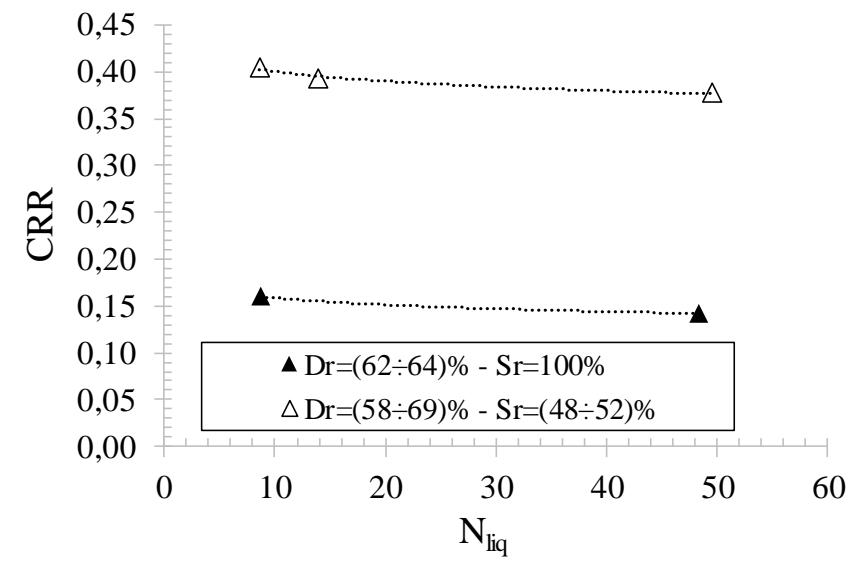

Figure10. Cyclic resistance curves for Inagi sand. 


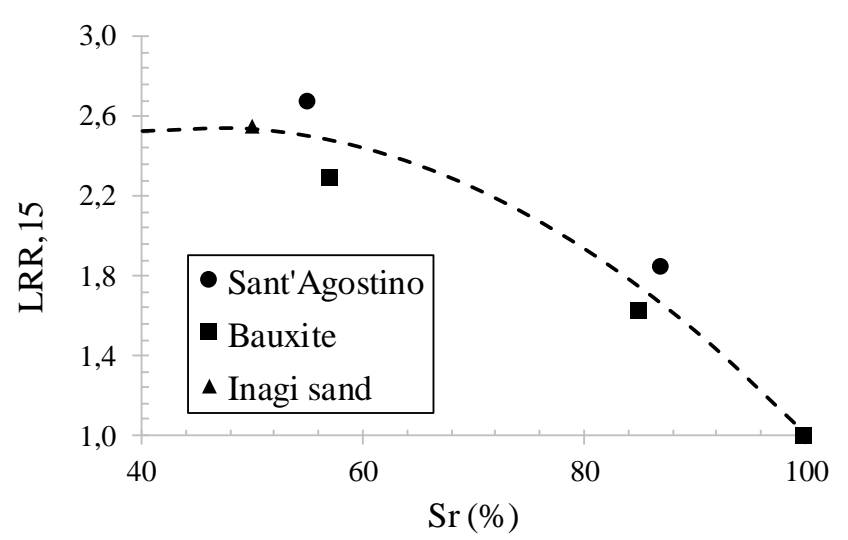

Figure 11. Liquefaction Resistance Ratio LRR versus degree of saturation Sr.

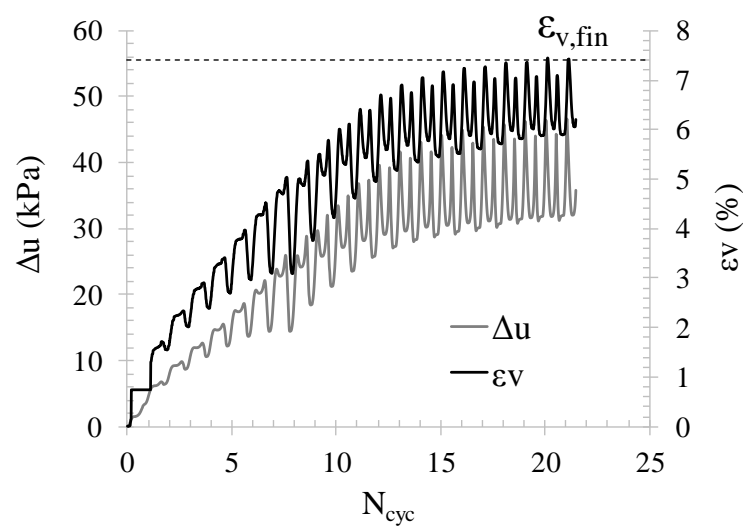

(a)

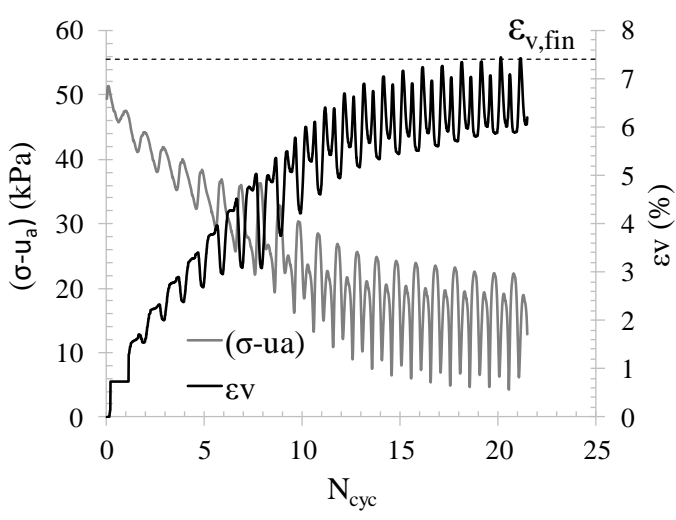

(b)

Figure $12(\mathrm{a}, \mathrm{b})$. Pore pressure, net stress and volumetric strain vs number of cycles (U_SA2).

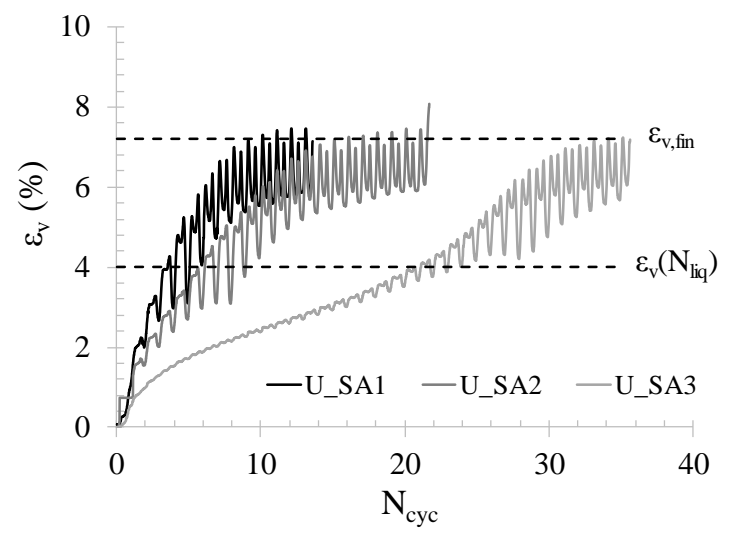

(a)

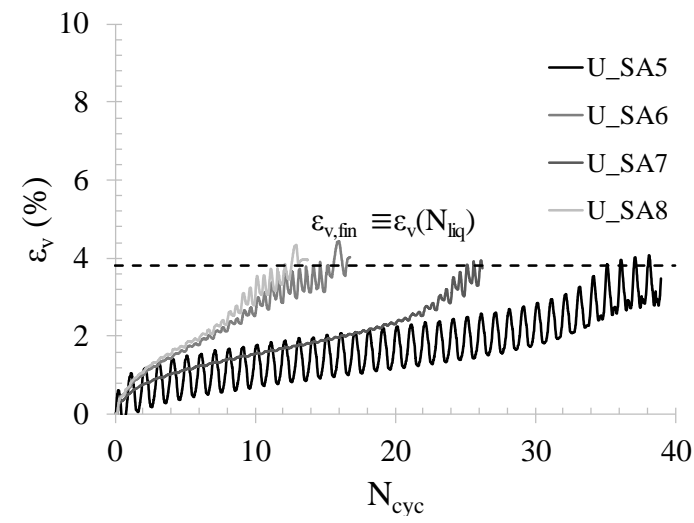

(b)

Figure $13(a, b)$. Volumetric strain versus number of cycles. 


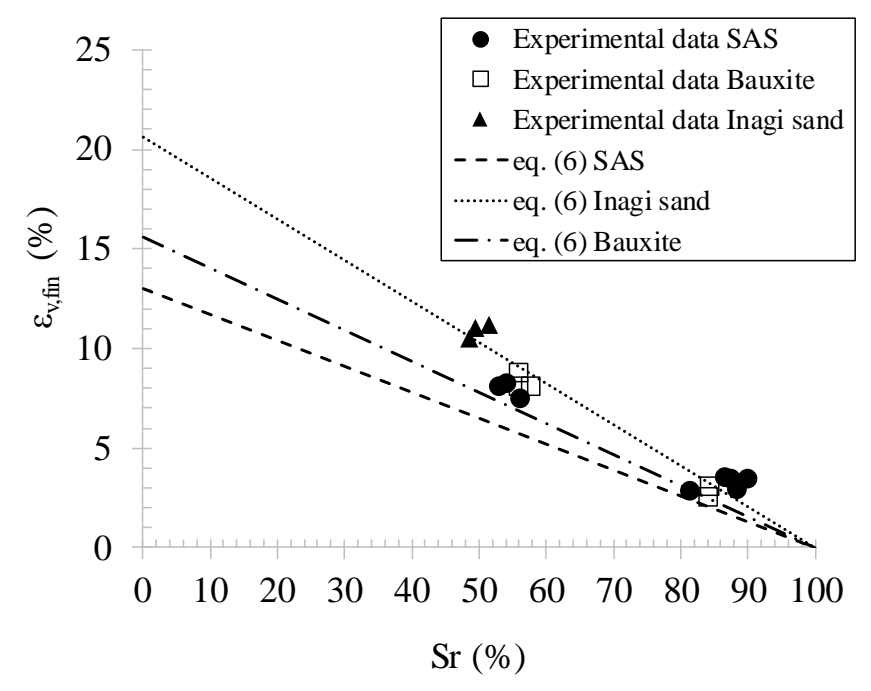

Figure 14. Final volumetric strain as a function of the initial degree of saturation: experimental data and theoretical correlations (eq. 6).

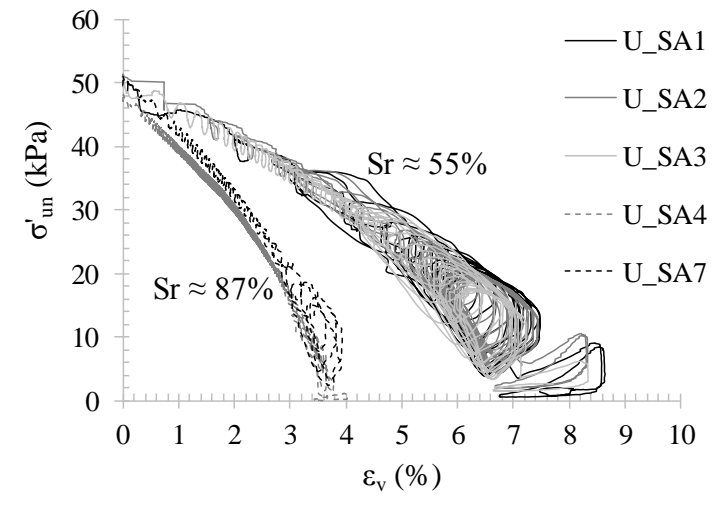

(a)

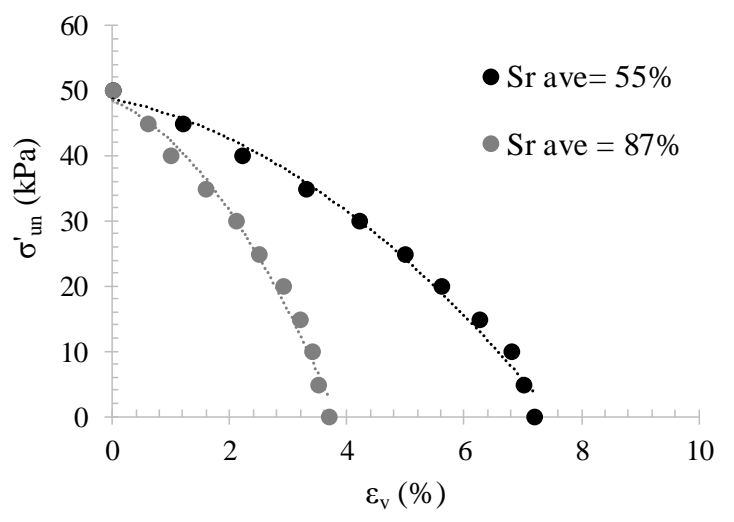

(b)

Figure 15. Volumetric strain versus net stress for different degrees of saturation.

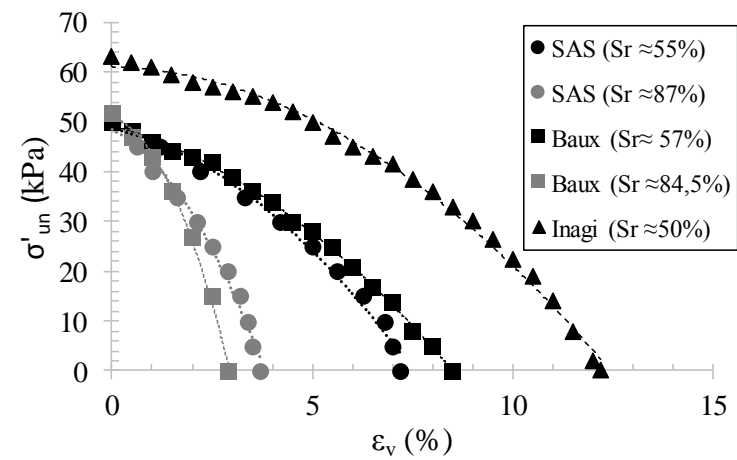

(a)

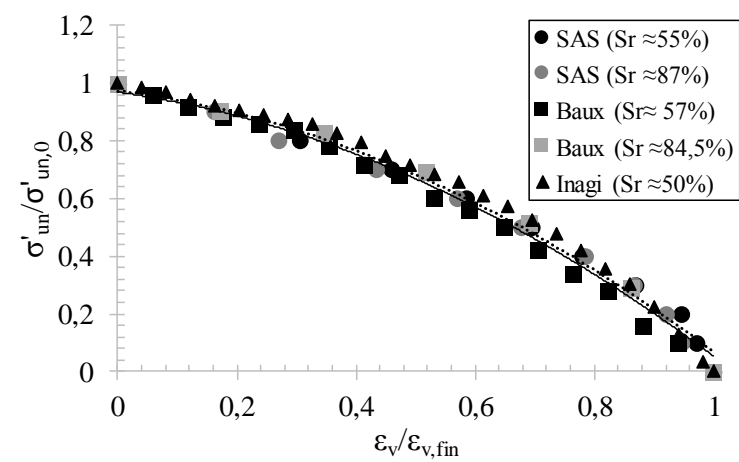

(b)

Figure $16(a, b)$. Effective stress with volumetric strain (a) and dimensionless effective stress versus dimensionless volumetric strain (b). 


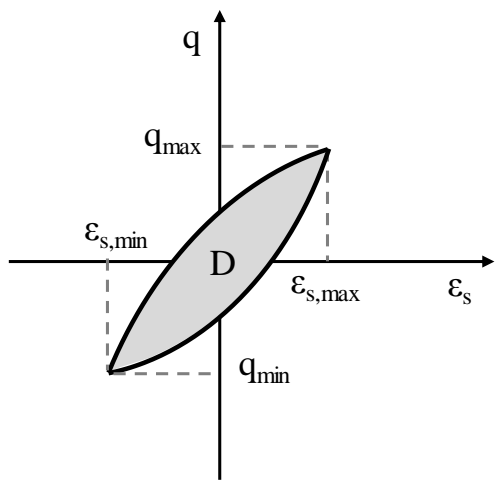

Figure 17. A stress cycle in the $q: \varepsilon_{s}$ plane, with the indication of the area $D$ used in eq. (12).

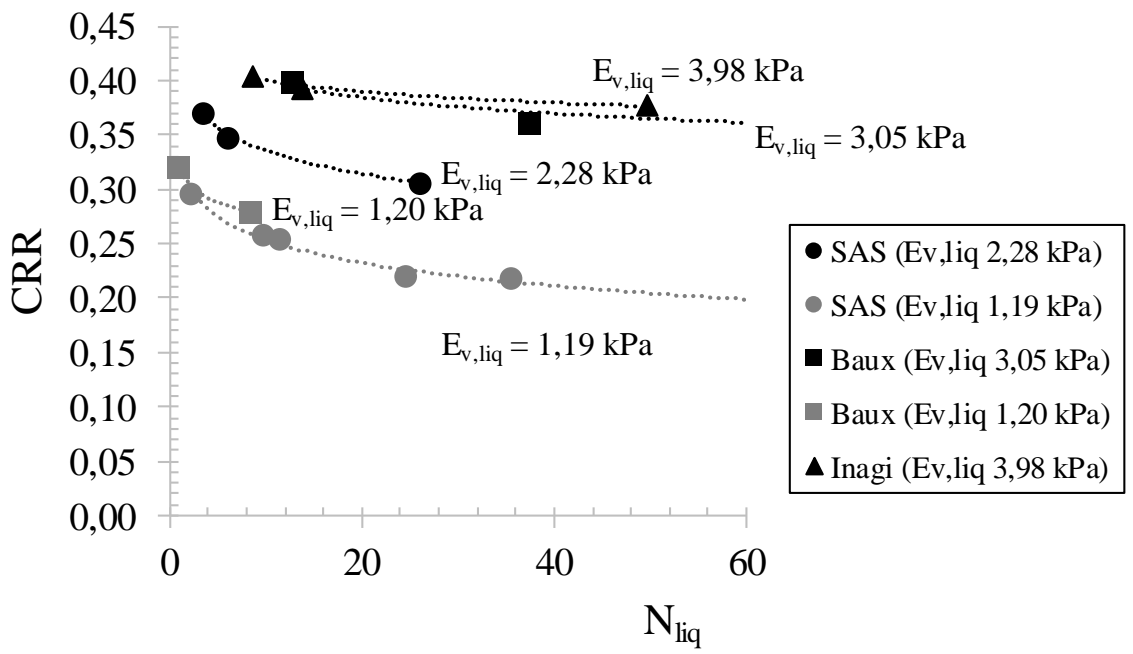

Figure 18. Cyclic resistance curve for values of $E_{v, l i q}$.

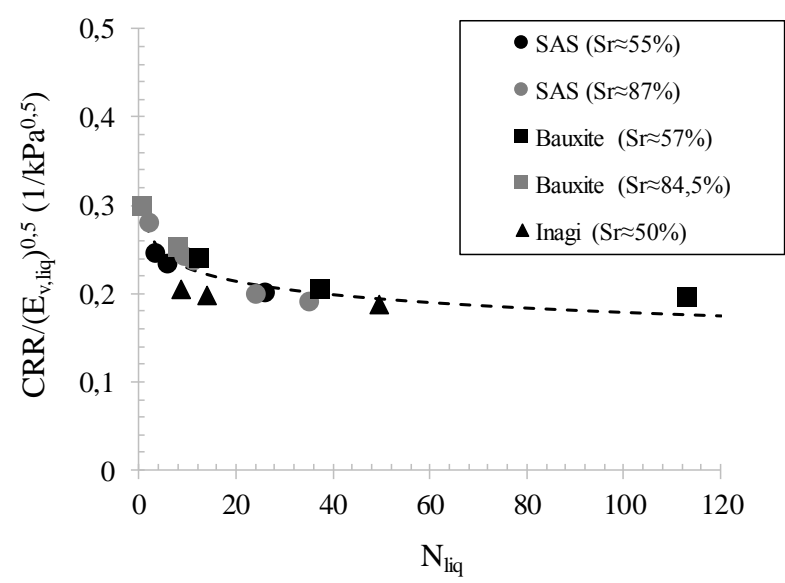

Figure 19. Normalized Cyclic Resistance Ratio versus $N_{\text {liq }}$ for unsaturated sands. 


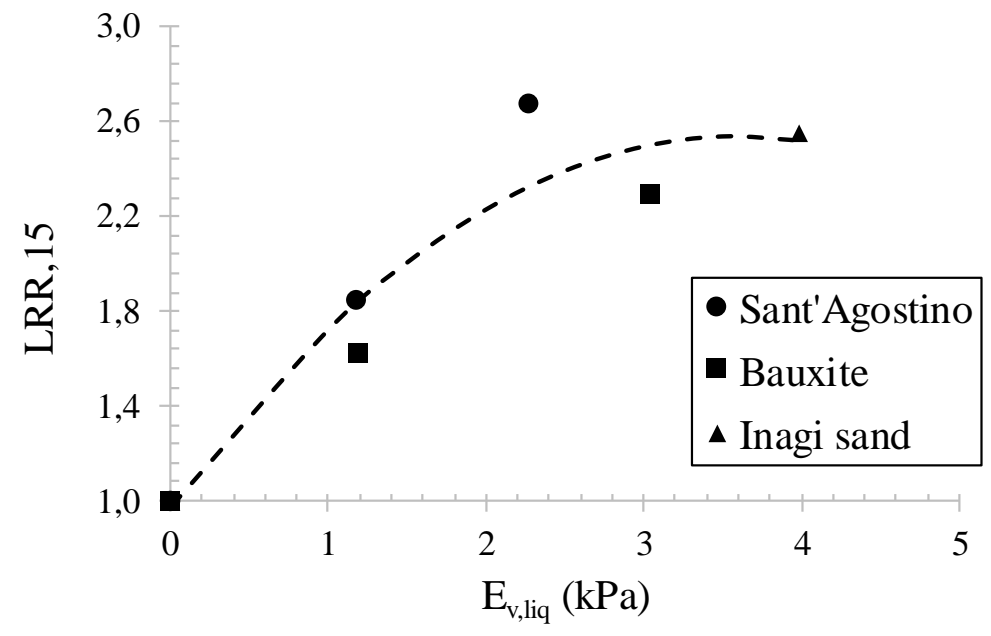

Figure 20. Liquefaction Resistance Ratio LRR versus $\mathrm{E}_{\mathrm{v}, \text { liq. }}$. 